OPEN ACCESS

Edited by:

Hanting Zhang,

West Virginia University,

United States

Reviewed by:

Jianfeng Xiao,

University of Tennessee Health

Science Center (UTHSC),

United States

Jianrong Tang,

Baylor College of Medicine,

United States

*Correspondence:

Wei Zheng

wzheng@cmu.edu.cn

tThese authors have contributed equally to this work and share first

authorship

Received: 27 April 2020 Accepted: 24 September 2020 Published: 10 November 2020

Citation: Lin G, Li X, Cheng X, Zhao N and Zheng W (2020) Manganese Exposure Aggravates $\beta$-Amyloid Pathology by Microglial Activation. Front. Aging Neurosci. 12:556008. doi: 10.3389/fnagi.2020.556008

\section{Manganese Exposure Aggravates $\beta$-Amyloid Pathology by Microglial Activation}

\author{
Geng Lin ${ }^{1 \dagger}$, Xinlu $\mathrm{Li}^{1 \dagger}$, Xiaofeng Cheng ${ }^{1}$, Ning Zhao ${ }^{2}$ and Wei Zheng ${ }^{1 *}$ \\ ${ }^{1}$ Department of Histology and Embryology, China Medical University, Shenyang, China, ${ }^{2}$ Shengjing Hospital of China Medical \\ University, Shenyang, China
}

Human epidemiological evidence and animal experimental data suggest that chronic manganese (Mn) exposure increases the risk of Alzheimer's disease (AD) and amyloid plaques, a hallmark of $A D$ brain pathology, but the underlying mechanisms were not fully understood. Using the transgenic APP/PS1/Tau triple transgenic AD (3×Tg-AD) mouse model and mouse-derived microglia and neuroblastoma cell lines, we found that chronic 5-month $\mathrm{Mn}$ treatment increased beta amyloid peptide $(A \beta)$ expression and $A \beta$ plaques in the cerebral cortex and hippocampus in these $3 \times$ Tg-AD mice. Furthermore, we found that the $\beta$ - and $\gamma$-secretase cleavage activities were markedly increased, while $\alpha$-secretase cleavage activity was reduced in the brain of Mn-treated AD mice; these effects increase $A \beta$ production and thus are amyloidogenic. Equally important, $M n$ treatment alone did not alter $\beta$-secretase 1 (BACE1) gene expression or $A \beta$ production in amyloidogenic mutant amyloid precursor protein (APP) gene hAPPsw-transfected N2a cells (APPsw-N2a), but in APPsw-N2a cells either co-cultured with microglia or cultured with microglia-conditioned media, Mn exposure increased BACE1 expression and amyloidogenesis. We further determined that $\mathrm{Mn}$ exposure promoted the activation of microglia both in $3 \times \mathrm{Tg}$-AD mouse brains and in cultured microglia cells, and increased

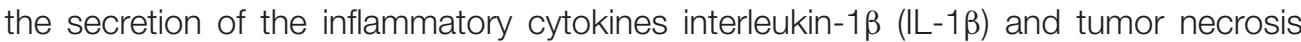
factor- $\alpha(T N F-\alpha)$. Taken together, these results suggest that Mn may increase the release of IL-1 $\beta$ and TNF- $\alpha$ from microglia that in turn stimulates the expression of BACE1 gene and protein and consequently $A \beta$ production; this novel molecular mechanism not only advances our understanding about the amyloidogenic effect of chronic $\mathrm{Mn}$ exposure reported for special human populations but also indicates $\mathrm{Mn}$ dyshomeostasis as a potential contributor to AD pathogenesis.

Keywords: Alzheimer's disease, $\beta$-amyloid, microglia, manganese, neuroinflammation, cytokines

\section{INTRODUCTION}

Alzheimer's disease (AD) is the most common dementia-causing neurodegenerative disease that inflicts 5.8 million senior people in the United States alone and 40 million senior people worldwide, and the patient population is increasing as the life expectancy increases (Alzheimer's Association, 2020). Thus, understanding the causes and risk factors 
for $\mathrm{AD}$ is critically important for the global fight against this disease. While old age is a key risk factor and abnormal $\mathrm{A} \beta$ and tau are key molecules causing $\mathrm{AD}$ neurodegeneration (Selkoe and Hardy, 2016; Forner et al., 2017; Walsh and Selkoe, 2020), other factors may also contribute to $\mathrm{AD}$ pathogenesis. One such contributing factor is a dyshomeostasis of essential biometals (e.g., iron, zinc, copper, and manganese; Jucker and Walker, 2013; Ciechanover and Kwon, 2015; Adlard and Bush, 2018; Soto and Pritzkow, 2018; Lermyte et al., 2019). Previous studies suggested that these biometals may disrupt and retard the metabolism, and facilitate the aggregation, of $\beta$-amyloid (A $\beta$ ) peptide and tau protein (Ayton et al., 2013; Guo et al., 2013; Tong et al., 2014; Ward et al., 2014; Li et al., 2017; Takeda et al., 2017; Cheignon et al., 2018), but firm conclusions and mechanisms about the functional roles of these essential biometals in $\mathrm{AD}$ pathogenesis are not established.

Manganese (Mn) is an essential trace metal in the human body and has important biochemical and physiological functions as it is a cofactor for several important enzymes, such as glutamine synthetase, pyruvate carboxylase, arginase, and Mn superoxide dismutase (Chen et al., 2015). However, elevated Mn levels can impair the function and structure of the brain, as demonstrated by the consequences from the sustained high Mn level after the inactivation of the transmembrane transporter for Mn (Bowler et al., 2007; Ellingsen et al., 2008; Guarneros et al., 2013; Jenkitkasemwong et al., 2018; Mukhopadhyay, 2018). $\mathrm{Mn}$ is present in the air, soil, and waterways and can enter the human body via breathing, food, and water (Horning et al., 2015; Peres et al., 2016). The healthy brain is capable of efficiently regulating $\mathrm{Mn}$ homeostasis under physiological conditions (Chen et al., 2015; Jenkitkasemwong et al., 2018; Mukhopadhyay, 2018; Taylor et al., 2019); however, Mn overexposure, due to excessive $\mathrm{Mn}$ in the natural environment and occupational environments such as mining and welding, can lead to its increased accumulation in the central nervous system. Mn accumulation in the basal ganglia and its associated neurotoxicity can result in manganism characterized by parkinsonian motor deficits (Yamada et al., 1986; Racette, 2014). Studies have also found cognitive deficits in human populations living near refineries with high Mn levels (Guarneros et al., 2013), and there is dose-effect relationships between $\mathrm{Mn}$ exposure and cognitive decline (Bowler et al., 2007; Ellingsen et al., 2008).

Furthermore, chronic Mn exposure was reported to increase the expression of amyloid-beta precursor-like protein 1 (APLP1) gene and protein, and the formation of diffuse $A \beta$ plaques in the frontal cortex of nonhuman primates (Guilarte et al., 2008; Guilarte, 2010). Additionally, Mn was shown to be at significantly higher levels in the brain of $\mathrm{AD}$ patients compared to healthy subjects, while the highest level was detected in the parietal cortex where AD pathology is severe (Srivastava and Jain, 2002; Tong et al., 2014; Cheignon et al., 2018), and there was a significant increase in $\mathrm{A} \beta$ peptides correlated with $\mathrm{Mn}$ both in the plasma of $\mathrm{AD}$ patients and in the brain of $\mathrm{AD}$ mouse models (Tong et al., 2014). Together, these literature data suggest that Mn overload may be a potential risk for $\mathrm{AD}$ and is involved in the pathogenesis of $\mathrm{AD}$ and cognitive dysfunction, but the underlying mechanisms for $\mathrm{Mn}$ to increase $\mathrm{A} \beta$ pathology are not fully established.
To further determine Mn's potential enhancement of $\mathrm{AD}$ pathology and the underlying molecular mechanisms, our present study investigates the effects of chronic Mn exposure on amyloid plaque formation in mutant APP/PS1/Tau triple transgenic $\mathrm{AD}$ mice and cultured cells expressing mutant amyloidogenic amyloid precursor protein (APP) and the involvement of brain innate immune cells, microglia; this combined approach enables us to study the potential Mn effects in intact brain tissues-conferring more pathophysiological relevance, and also in isolated cultured cells-allowing more detailed cellular and molecular analyses.

\section{MATERIALS AND METHODS}

\section{Transgenic Mice and Mn Treatment Regimen}

Breeders of the APP/PS1/Tau triple transgenic AD $(3 \times \mathrm{Tg}-\mathrm{AD})$ mouse model, originally created by Oddo et al. (2003), was obtained from the Jackson Laboratory (Stock No.: 34830, Bar Harbor, ME, USA). All mice were kept in a controlled environment $\left(22-25^{\circ} \mathrm{C}\right.$ room temperature, $12 \mathrm{~h}$ light/dark cycle, and $40-60 \%$ relative humidity) with free access to water and food. The Laboratory Animal Ethics Committee of China Medical University approved all experimental procedures. Only male mice were used because cyclic hormonal changes in female mice may affect the production, metabolism, and accumulation of APP and $A \beta$ and consequently confound data interpretation. Future studies need to investigate the potential sex differences in Mn effects on amyloidogenesis.

Because in $3 \times \mathrm{Tg}-\mathrm{AD}$ mice, amyloidogenesis and $\mathrm{A} \beta$ pathology progress through 2-26 months (Oddo et al., 2003; Mastrangelo and Bowers, 2008), we chose 8 months of age as the starting point. Thus, 8 -month-old male $3 \times \mathrm{Tg}$ - $\mathrm{AD}$ mice were randomly divided into two groups: mice of Mn group were provided with $\mathrm{Mn}$-containing drinking water (108 mg $\mathrm{MnCl}_{2} \bullet 4 \mathrm{H}_{2} \mathrm{O}$ dissolved in $300 \mathrm{ml}$ of distilled drinking water; $\mathrm{MnCl}_{2} \bullet 4 \mathrm{H}_{2} \mathrm{O}, 99 \%$ purity was purchased from Sigma-Aldrich, St. Louis, MO, USA); mice of the Control group were provided with distilled drinking water. Mice were monitored daily, and their body weight was measured and recorded weekly. At the end of the 5-month-treatment, whole blood samples were collected directly from the heart of the mice deeply anesthetized with intraperitoneally injected $4 \%$ chloral hydrate at $0.1 \mathrm{ml} / 10 \mathrm{~g}$ of body weight, and the serum was prepared; this blood collection method is well established for collecting the maximal amount of blood with minimal contamination. The Mn concentrations in sera and brains were determined using mass spectrometry as detailed below.

\section{Cell Culture}

Mouse N2a neuroblastoma cells stably transfected with human Swedish mutant APP (abbreviated as APPsw-N2a cells for convenience) were provided by Dr. Huaxi Xu of Sanford Burnham Prebys Medical Discovery Institute, USA. Mouse BV2 microglia cells were provided by Dr. Yuhua Chen of China Medical University. The APPsw-N2a cells were maintained 
in 6-cm tissue culture dishes in normal DMEM medium supplemented with $10 \%$ fetal bovine serum (Gibco, Carlsbad, CA, USA) and selected by $200 \mu \mathrm{g} / \mathrm{ml}$ of G418, following the methods in the literature (Guo et al., 2017). For studying the impact of $\mathrm{Mn}$ and inflammatory factors on the amyloidogenesis of APPsw-N2a cells, these cells were treated with 0, 100, and $500 \mu \mathrm{M} \mathrm{MnCl} 2$ for $24 \mathrm{~h}$, then the cells were collected for analyses.

\section{Transwell Coculture APPsw-N2a Cells With BV2 Microglia Cells}

To study the effects of microglia-secreted factors on APP processing, BV2 microglia were seeded onto permeable Transwell cell culture inserts (BD Biosciences, Franklin Lakes, NJ, USA) at $1 \times 10^{5}$ cells/well, APPsw-N2a cells were at $1 \times 10^{6}$ cells/well, and they were allowed to adhere for $48 \mathrm{~h}$. These Transwell inserts are permeable to cell/microglia-secreted factors, while the cultured cells in the two compartments do not mix and can be collected separately. Cell culture medium was changed to fresh serum-free Mn-free DMEM $24 \mathrm{~h}$ prior to treatment. BV2 inserts were placed into six-well culture plates seeded with APPsw-N2a, and both were treated with either 0 or $100 \mu \mathrm{M}$ Mn for $24 \mathrm{~h}$. Then the APPsw-N2a cells were collected for Western blot analysis.

\section{Microglia-Conditioned Cell Culture Media Preparation}

BV2 microglia cells were seeded onto six-well tissue culture plates at $1 \times 10^{5}$ cells/well and treated with 0 and $100 \mu \mathrm{M} \mathrm{MnCl}_{2}$ for $24 \mathrm{~h}$. Then the culture supernatants as microglia-conditioned media (MCM) were aspirated and centrifuged at $800 \times g$ for 10 min to remove detached cells. MCM was fed to APPsw-N2a cells cultured in 60 -mm tissue culture dishes at $1 \times 10^{6}$ cells/well with no additional $\mathrm{Mn}$ added for another $24 \mathrm{~h}$. The 1:10 ratio of microglia to neurons was utilized based on previous reports (Pelvig et al., 2008; Correa et al., 2013; Herculano-Houzel, 2014).

\section{Measurement of Brain Mn Levels}

We used an inductively coupled plasma mass spectrometer (ICP-MS; model 7500a, Agilent Technologies Inc., CA, USA) to measure the Mn level in brain tissues. The cortical and hippocampal tissue samples (20 $\mathrm{mg}$ for each wet tissue sample) were digested by adding $500 \mu \mathrm{l}$ of nitric acid; then the completely digested samples were diluted 20 times. Following the user manual, the instrument was operated at a radiofrequency power of $1,420 \mathrm{~W}$, the argon carrier gas flow rate was $1.05 \mathrm{l} / \mathrm{min}$, and the argon plasma gas flow rate was $15 \mathrm{l} / \mathrm{min}$. Using the peak area mode, the data acquisition time was $2 \mathrm{~s}$, and three measurements were repeated. ICP-MS measurements of Mn in blood and brain tissue samples were converted to concentrations based on the calibration curve and its linear fit equation and sample dilution (Figure 1B). The reliability of our measurements is confirmed by the fact that our baseline Mn levels were similar to the blood and brain Mn levels reported in the literature (Garcia et al., 2006; Moldovan et al., 2013; Jenkitkasemwong et al., 2018).

\section{Cytotoxicity Assay}

Mn cytotoxicity was assessed by cell counting kit-8 (CCK-8; Cat.\# B34304, Bimake, Houston, TX, USA) following the manufacturer's instructions. Wild-type N2a cells were seeded in a 96-well plate at a density of $5 \times 10^{4}$ cells/well in $100 \mu \mathrm{l}$ of culture medium and were cultured for $24 \mathrm{~h}$. Then the culture medium was changed to serum-free medium containing $\mathrm{MnCl}_{2}$ at 50,100, 200,500,800, and 1,000 $\mu \mathrm{M}$. The cells were cultured in a $\mathrm{CO}_{2}$ incubator at $37^{\circ} \mathrm{C}$ for another $24 \mathrm{~h}$. Ten microliters of CCK8 was added to the culture for $2 \mathrm{~h}$ at $37^{\circ} \mathrm{C}$. The optical density (OD) was measured at $450 \mathrm{~nm}$ with a microplate reader (Infinite 200 Pro, TECAN, Grödlg, Austria). Cell viability was calculated using the method described in the CCK-8 kit. Following the method of Daoust et al. (2014), a linear fit to the cell viability data points estimated the $50 \%$ lethal concentration $\left(\mathrm{LC}_{50}\right)$ to be $687.0 \mu \mathrm{M} \mathrm{MnCl}_{2}$ for $\mathrm{N} 2 \mathrm{a}$ cells under our experimental condition, roughly similar to the

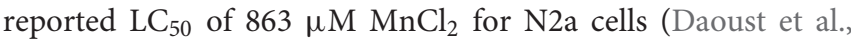
2014); at $100 \mu \mathrm{M}, \mathrm{Mn}$ did not induce any detectable cytotoxicity. Thus, we used $100 \mu \mathrm{M} \mathrm{MnCl}_{2}$ in most of our experiments on cultured cells.

\section{Immunofluorescence}

For double-immunofluorescent staining and confocal microscopic analysis, frozen sections were preincubated with normal sheep serum for $1 \mathrm{~h}$ and then incubated overnight at $4^{\circ} \mathrm{C}$ in a mixture of primary antibodies for mouse anti-A $\beta(1: 1,000)$ and rabbit anti-Iba1 (1:500). After several rinses with PBS, the sections were incubated for $2 \mathrm{~h}$ at room temperature with a mixture of FITC (green) and TRITC (red)-conjugated secondary antibodies (1:400; ZSGB-BIO, Los Altos, CA, USA) followed by mounting and coverslipping. The images were observed and captured using a confocal laser scanning microscope (Nikon C1, Tokyo, Japan). The fluorescence signal was absent when the primary antibody was omitted, indicating the specificity of the antibody. The primary antibodies used in this study, their sources, and dilutions are listed in Table 1.

\section{Western Blot}

After addition of the protease inhibitor cocktail, the samples were subjected to immunoblot analysis. The protein concentration was measured with a bicinchoninic acid (BCA) protein assay kit (Cat.\# P0012, Beyotime, Shanghai, China). The total protein lysate $(30 \mu \mathrm{g})$ was separated via $10 \%$ sodium dodecyl sulfate (SDS) polyacrylamide gels and transferred on polyvinylidene fluoride (PVDF) sheets (Millipore, Burlington, MA, USA). The membranes were blocked by $5 \%(\mathrm{w} / \mathrm{v})$ nonfat milk. The following antibodies were used: rabbit anti- $\beta$-amyloid (D54D2; 1:1,000, Cat.\# 8243S; Cell Signaling, MA, USA), mouse anti-APP (1:1,000, Cat.\# NAB228, Cell Signaling, MA, USA), mouse anti-presenilin 1 (1:1,000, Cat.\# Ab15456; Abcam, MA, USA), rabbit anti-ADAM10 (1:1,000, Cat.\# AB19026; Millipore, Burlington, MA, USA), rabbit anti-BACE (D10E5; 1:1,000, Cat.\# 5606S; Cell Signaling, MA, USA), rabbit anti-TNF- $\alpha$ (1:1,000, Cat.\# 17,590-1-AP, Proteintech, USA), rabbit anti-IL-1 $\beta$ (1:1,000, Cat.\# 16,806-1-AP, Proteintech, Chicago, IL, USA), and mouse anti- $\beta$-actin (1:10,000, Cat.\# A1978, Sigma-Aldrich, St. 


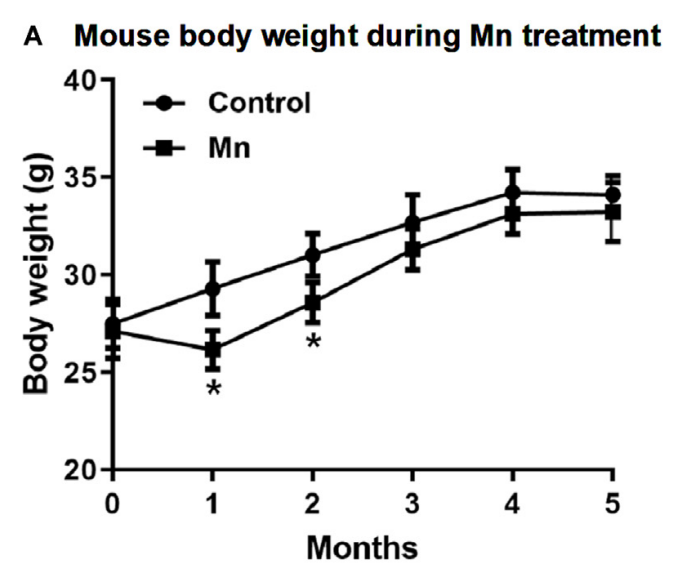

\section{B ICP-MS calibration curve for Mn}

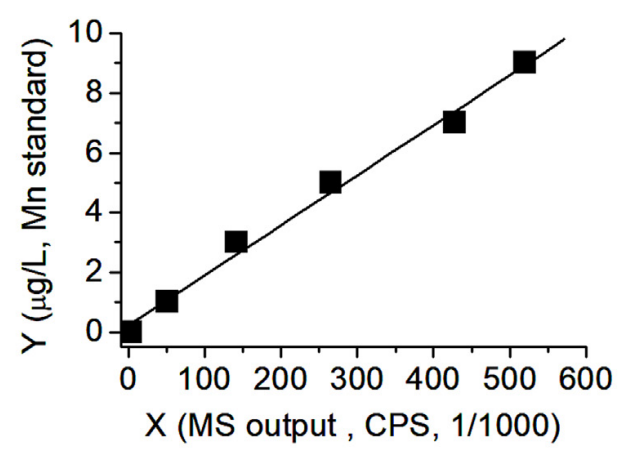

C Mn in serum

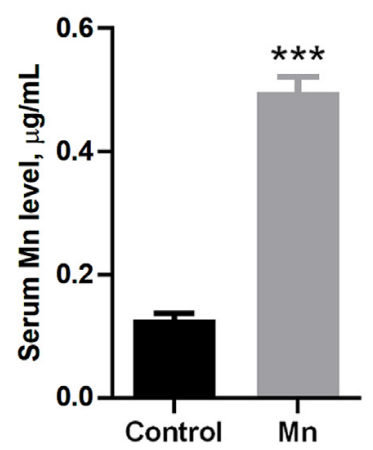

D Mn in cortex

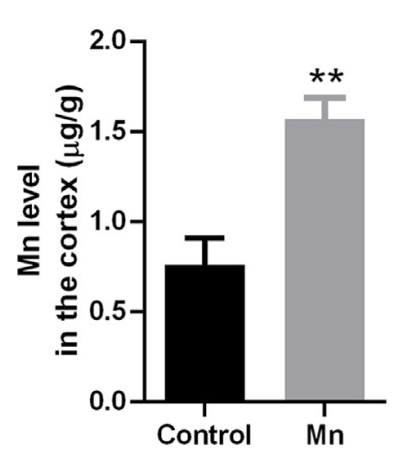

E Mn in hippocampus

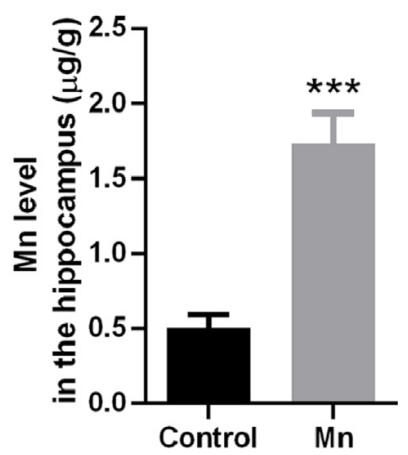

FIGURE 1 | Manganese (Mn) treatment via Mn-containing drinking water increased Mn concentrations in sera and brains in $3 \times$ Tg-AD mice. (A) The body weights of the mice were decreased in the $\mathrm{Mn}$ group in the first and second month, and then regained their weights in the following 3 months. $N=10$ male $3 \times$ Tg-AD mice for each group. ${ }^{*} p<0.05$, repeated measure (RM) ANOVA. Additional male $3 \times T g-A D$ mice were similarly treated, but their body weight was only measured before euthanization and was normal. (B) Inductively coupled plasma mass spectrometer (ICP-MS) calibration curve using Mn standards. (C,D) ICP-MS measurements of

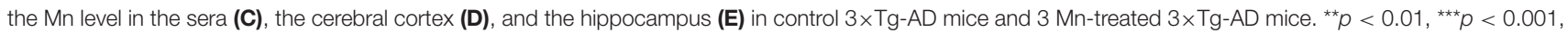
t-test.

TABLE 1 | Primary antibodies.

\begin{tabular}{|c|c|c|c|c|c|}
\hline Antibody name & Dilution & Host & Source/vendor & Cat no. & Application \\
\hline ADAM10 & $1: 1,000$ & Rabbit & Millipore & AB 19026 & Western blotting \\
\hline APP & $1: 1,000$ & Mouse & Cell Signaling & NAB228 & Western blotting \\
\hline BACE (10E5) & $1: 1,000$ & Rabbit & Cell Signaling & $5606 S$ & Western blotting \\
\hline lba1 & $1: 500$ & Rabbit & Wako & 019-19741 & $\mathrm{IHC}$ \\
\hline $\mathrm{IL}-1 \beta$ & $1: 1,000$ & Rabbit & Proteintech & 16806-1-AP & Western blotting \\
\hline Presenilin-1 & $1: 1,000$ & Mouse & Abcam & ab15456 & Western blotting \\
\hline TNF- $\alpha$ & $1: 1,000$ & Rabbit & Proteintech & 17590-1-AP & Western blotting \\
\hline$\beta$-actin & $1: 10,000$ & Mouse & Sigma-Aldrich & A1978 & Western blotting \\
\hline$\beta$-amyloid & $1: 1,000$ & Mouse & Sigma-Aldrich & A5213 & $\mathrm{HC}$ \\
\hline$\beta$-amyloid (D54D2) & $1: 1,000$ & Rabbit & Cell Signaling & $8243 s$ & Western blotting \\
\hline
\end{tabular}

Louis, MO, USA). After washing three times with Tris-buffered saline containing Tween-20 for $5 \mathrm{~min}$ each, the membranes were incubated with appropriate HRP-conjugated secondary antibodies (1:5,000; Cell Signaling, MA, USA) for $1 \mathrm{~h}$ at room temperature. Membranes were washed for $5 \mathrm{~min}$ three times with TBST after incubation with each antibody. Finally, immunological complexes were visualized by an enhanced chemiluminescence reagent (Cat.\# 34080, Pierce, Thermo Fisher Scientific, Waltham, MA, USA) using a ChemiDoc XRS system
(Tanon-5200, BioTannon Company, Shanghai, China). The immunoreactive bands were quantified using Image-pro Plus 6.0 analysis software. The antibodies used for Western blot are listed in Table 1.

\section{Enzyme-Linked Immunosorbent Assay}

The production of soluble A $\beta 1-40$ (RayBiotech, Norcross, GA, USA), A $\beta 1-42$ (Cusabio Biotech LLC, Houston, TX, USA), TNF- $\alpha$ (eBioscience Inc., San Diego, CA, USA) and 
IL-1 $\beta$ (eBioscience Inc., San Diego, CA, USA) in the culture supernatants was measured by enzyme-linked immunosorbent assay (ELISA) following the manufacturer's instructions.

\section{Semiquantitative RT-PCR of mRNAs}

Total RNA was isolated using Trizol reagent (Invitrogen, Cat.\# 15596018) according to the product's user instructions. RNA purity and quality was monitored by $260 / 280 \mathrm{~nm}$ OD ratios. The cDNA was synthesized from $2 \mu \mathrm{g}$ total RNA using the GoScript Reverse Transcription System (Cat.\# A5003, Promega, Madison, WI, USA) on the Bio-Rad CFX PCR System. The primer sequences are listed in Table 2. The housekeeping gene GAPDH was used as an internal control. The relative mRNA expression level was calculated by Bio-Rad CFX software using the $\triangle \triangle$ Ct method (Heid et al., 1996; Xue et al., 2015).

\section{Statistical Analyses}

The results are represented as mean \pm SEM. All statistical analysis was performed using GraphPad Prism 6.0 software (GraphPad Software, Inc., San Diego, CA, USA). Student's $t$ test was used for comparison of two groups. One-way ANOVA followed by a Tukey-Kramer multiple comparison post hoc test was utilized for comparison of three or more groups. Two-way ANOVA followed by Tukey-Kramer multiple comparison post hoc tests was adopted for comparison of three or more groups and two different variables in analyzing N2a cell responses in coculture and conditioned media experiments. Independent variables for two-way ANOVA were defined as treatment (normal drinking water vs. Mn-containing drinking water) and microglial presence ( $\mathrm{Mn}$ alone vs. microglia $+\mathrm{Mn}$ ). Repeated measure ANOVA (RM ANOVA) was used for comparing the body weight of the two groups of mice at different time points. A value of $p<0.05$ was considered as statistically significant.

\section{RESULTS}

\section{Chronic Oral Mn Administration Increases Blood and Brain Mn Concentrations}

We first measured and analyzed the body weight of $3 \times \mathrm{Tg}-\mathrm{AD}$ mice receiving $\mathrm{Mn}$ in their drinking water. The body weight of the mice in Mn group was lower than that of the control group at the end of the first month and the second month $(p<0.05$, RM ANOVA; Figure 1A); the body weight of the two groups was not significantly different during the next 3 months

TABLE 2 | RT-PCR primers (for mouse genes).

ADAM10 forward: GCACCTGTGCCAGCTCTGAT

ADAAM10 reverse: TCCGACCATTGAACTGCTTGT

APP forward: TGATCTACGAGCGCATGAAC

APP reverse: AGA AGGCATGAGAGCATCGT

BACE1 forward: GGATTATGGTGGCCTGAGCA

BACE1 reverse: CGTGTCCACCAGGATGTTGA

GAPDH forward: TTCACCACCATGGAGAAGGC

GAPDH reverse: GGCATGGACTGTGGTCATGA

PS1 forward: GCCCCAGAGTAACTCAAGACA

PS1 reverse: CCGGGTATAGAAGCTGACTGA
( $p>0.05$, RM ANOVA; Figure 1A). Because a metallic taste of Mn-containing water is well documented (Thomsen et al., 2004; Saha et al., 2015), we speculate that the lower body weight in the first 2 months might be because the mice did not like the Mncontaining, metallic-tasting Mn-containing drinking water and drank and ate less-although we did not monitor the water and food intake; and after the first 2 months, these mice became used to the Mn-containing drinking water, drank and ate normally, and regained their body weight. Indeed, a similar drinking water $\mathrm{Mn}$-induced body weight loss was reported in normal mice in a previous study (Krishna et al., 2014) that showed that drinking water Mn initially reduced water intake and body weight, but these effects disappeared after 7 weeks.

Our mouse experiments below were conducted at the end of the 5-month Mn treatment when the $3 \times \mathrm{Tg}-\mathrm{AD}$ mice in the Mn treatment group had normal body weight, and their general peripheral health was likely comparable to that of the control (non-Mn treated) $3 \times$ Tg-AD mice.

We next used ICP-MS to determine Mn levels in sera and brains of $3 \times \mathrm{Tg}-\mathrm{AD}$ mice (Figure 1B). The serum $\mathrm{Mn}$ level in the Mn-treated group of $3 \times \mathrm{Tg}$-AD mice was $0.496 \pm 0.015$ $\mu \mathrm{g} / \mathrm{ml}$ ( $n=3$ mice), compared with the control group's $0.128 \pm 0.006 \mu \mathrm{g} / \mathrm{ml}$ ( $n=3$ mice, $p<0.001$, $t$-test; Figure 1C). The $\mathrm{Mn}$ level in the cerebral cortex (parietal area) was $1.57 \pm 0.07 \mu \mathrm{g} / \mathrm{g}$ wet tissue in the Mn-treated $3 \times \mathrm{Tg}-\mathrm{AD}$ mice $(n=3)$ and $0.75 \pm 0.09 \mu \mathrm{g} / \mathrm{g}$ wet tissue in the control group $(n=3)$; the hippocampus Mn level was $1.74 \pm 0.12 \mu \mathrm{g} / \mathrm{g}$ wet tissue in the Mn-treated $3 \times \mathrm{Tg}-\mathrm{AD}$ mice $(n=3)$ and $0.51 \pm 0.05 \mu \mathrm{g} / \mathrm{g}$ wet tissue in the control group $(n=3)$. Statistical analysis showed that long-term Mn administration via drinking water significantly increased the $\mathrm{Mn}$ concentrations both in the cortex and in the hippocampus $(n=3, p<0.01, t$-test; Figures 1D,E). Also, our baseline blood and brain Mn levels were similar to the reported values (Garcia et al., 2006; Moldovan et al., 2013; Jenkitkasemwong et al., 2018), indicating the reliability of our Mn measurements.

\section{Effects of Chronic Mn Treatment on APP and $A \beta$ Expression in $3 \times \mathrm{Tg}-\mathrm{AD}$ Mouse Brains}

To test whether high brain Mn affects APP expression, the levels of APP mRNA and full-length APP protein were measured by semiquantitative RT-PCR and Western blot, respectively. As shown in Figure 2A, APP mRNA levels were increased both in the cerebral cortex (to $221.50 \pm 40.20 \%, n=5$ ) and in the hippocampus (to $191.20 \pm 13.16 \%, n=5$ ) of the Mn group compared with the control ( $p<0.05, n=5, t$-test). Western blot analysis showed that Mn treatment significantly increased APP protein level to $447.58 \pm 95.45 \%$ in the cerebral cortex $(n=5)$ and to $439.10 \pm 50.79 \%$ in the hippocampus $(n=5)$, compared with control group ( $n=5, p<0.05, t$-test; Figures $2 B, C)$.

To determine whether long-term oral $\mathrm{Mn}$ intake altered $\mathrm{A} \beta$ levels in the brain of $3 \times \mathrm{Tg}-\mathrm{AD}$ mice, an $\mathrm{A} \beta$ antibody (Cat.\# 8243s, Cell Signaling Technology, see Table 1) was used in Western blot for detecting and quantifying $A \beta$ fragments (Figure 2B). Statistical analysis showed that the chronic Mn 


\section{A Semiquantitative RT-PCR}

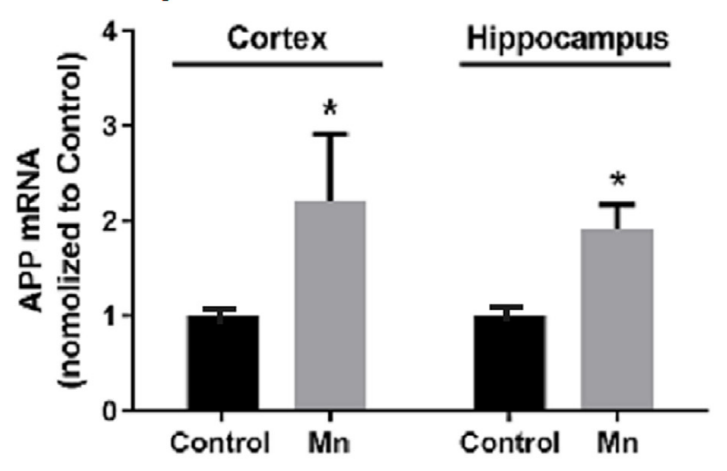

\section{B Western blot}
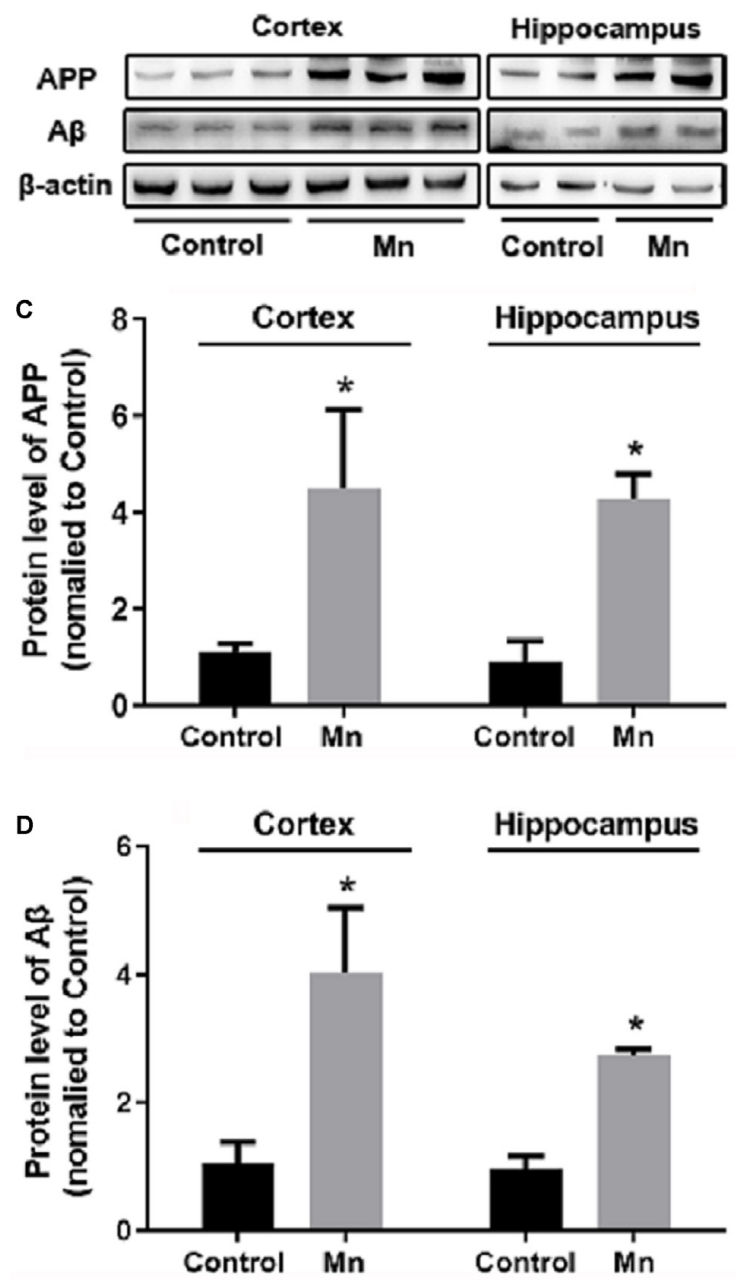

FIGURE 2 | Chronic Mn treatment increased $\beta$-amyloid $(A \beta)$ production in $3 \times$ Tg-AD mouse brains. (A) APP mRNA level in $3 \times$ Tg-AD mouse brains, determined by semiquantitative RT-PCR with GAPDH mRNA serving as the internal control, was increased in the cerebral cortex and hippocampus of Mn-treated $3 \times$ Tg-AD mice. (B-D) The protein expression of APP and A $\beta$ in $3 \times \mathrm{Tg}-\mathrm{AD}$ mouse brain, determined by Western blot, was increased in the cortex and hippocampus of Mn-treated $3 \times \mathrm{Tg}$-Ad mice. $\beta$-actin was used as the internal control. $n=5$ mice for each group. ${ }^{\star} p<0.05$, compared with the control group, $t$-test. treatment via drinking water significantly increased the $\mathrm{A} \beta$ level to $402.17 \pm 106.92 \%$ in the cerebral cortex $(n=5)$ and to $278.27 \pm 12.40 \%$ in the hippocampus $(n=5)$, compared with the control group ( $n=5, p<0.05, t$-test; Figures 2B,D). Taking together, our data presented above indicate that high brain $\mathrm{Mn}$ increased both APP gene and protein expression and also A $\beta$ production and accumulation. The question now is: how?

\section{Mn Effects on Amyloidogenic APP Processing in $3 \times \mathrm{Tg}-\mathrm{AD}$ Mice}

To examine how high $\mathrm{Mn}$ intake increased amyloidogenic APP processing, qRT-PCR and Western blot analyses were performed to detect and quantify the key enzymes in APP processing including BACE1 ( $\beta$-secretase activity producing $A \beta)$, ADAM10 (a key component of $\alpha$-secretase activity), presenilin 1 (PS1, a key component of $\alpha$-secretase activity producing $A \beta$ ), and APP cleavage fragments including C99 and C83, in the cortex and hippocampus of control and Mn-treated $3 \times \mathrm{Tg}-\mathrm{AD}$ mice. As shown in Figure 3, Mn treatment significantly increased protein levels of $\beta$-secretase 1 BACE1 in the cerebral cortex and hippocampus of $3 \times \mathrm{Tg}-\mathrm{AD}$ mice $(p<0.05, t$-test; Figures $3 \mathbf{A}, \mathbf{B})$; in contrast, protein levels of ADAM10 in the cortex and hippocampus of $3 \times \mathrm{Tg}-\mathrm{AD}$ mice were decreased significantly after $\mathrm{Mn}$ treatment $(n=5, p<0.05$, $t$-test; Figures 3A,C). Furthermore, the levels of PS1 in Mn-treated $3 \times \mathrm{Tg}-\mathrm{AD}$ mouse hippocampus and cortex were significantly increased compared with the control group $(n=5, p<0.05$, $t$-test; Figures 3A,D). Then we examined the levels of $\beta$ secretase-generated C99 fragment and $\alpha$-secretase-generated C83 fragment in $3 \times \mathrm{Tg}-\mathrm{AD}$ mouse brains. Mn treatment significantly increased the levels of C99 fragment $(n=5$, $p<0.05$, $t$-test; Figures 3E,F) and reduced the levels of C83 fragment ( $p<0.05$; Figures 3E,G). Taken together, these results indicate that the $\beta$ - and $\gamma$-secretase cleavage activities were markedly increased, while $\alpha$-secretase cleavage activity was reduced in the cerebral cortex and hippocampus of Mn-treated $3 \times \mathrm{Tg}-\mathrm{AD}$ mice, and these chronic $\mathrm{Mn}$ treatment-induced changes are amyloidogenic.

\section{Mn Effects on Amyloidosis in N2a Cells Transfected With hAPPsw Requires Coculture With Microglia}

Next, we performed experiments in a mouse neuroblastoma $\mathrm{N} 2 \mathrm{a}$ cell line stably transfected with amyloidogenic mutant APP hAPPsw gene (Guo et al., 2017) to further investigate the molecular mechanisms by which chronic Mn treatment affects APP processing for increased amyloidogenic A $\beta$ production. Mn concentrations of $100 \mu \mathrm{M}$ were used in most of our experiments, although $500 \mu \mathrm{M}$ Mn was used for some experiments, based on the evaluation of cell viability assay and previous studies (LC50 800 $\mu \mathrm{M}$ : Daoust et al., 2014; Wang et al., 2017; Yin et al., 2018). Surprisingly, Mn exposure at these concentrations did not change the levels of APP cleavage enzymes (ADAM10, BACE1, and PS1) in APPsw-N2a cells $(n=5, p>0.05$, one-way ANOVA; Figures 4A-D); neither the level of APP protein nor its C-terminal fragment intermediates C99 and C83 were changed in APPsw-N2a cells ( $n=5, p>0.05$, one-way ANOVA; 

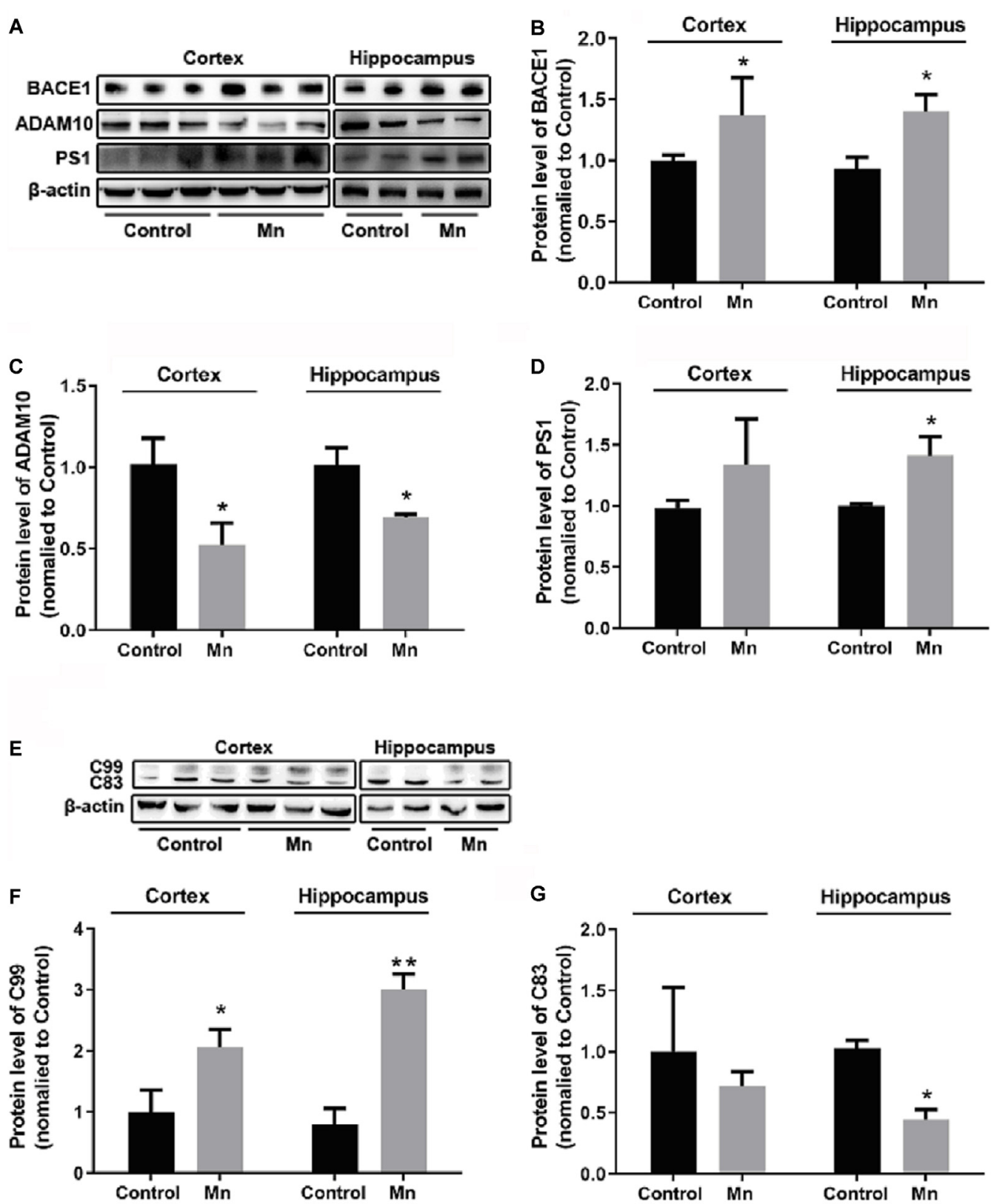

FIGURE 3 | Mn exposure promoted amyloidogenic APP processing in 3xTg-AD mouse brains. (A-D) The expression levels of BACE1, ADAM10, and $\gamma$-secretase PS1 in the brain of Alzheimer's disease (AD) were examined by Western blot. The protein levels of BACE1 and PS1 were significantly increased (B,D), whereas ADAM10 were markedly decreased (C) in the cortex and hippocampus of Mn-exposure mice. (E-G) Western blot analysis of the expression of intracellular APP cleavage fragments, including C99 and C83, in the brain of AD mice treated with or without Mn. Mn exposure significantly increased the levels of C99 both in the cortex and hippocampus, and reduced the levels of C83 in hippocampus. $\beta$-actin served as the internal control. $n=5$ mice for each group, ${ }^{*} p<0.05,{ }^{* *} p<0.01$, compared with the control group, $t$-test.

Figures $4 \mathrm{E}-\mathrm{H})$. These results indicate that by itself, $\mathrm{Mn}$ was insufficient to affect $A \beta$ production in APPsw-N2a cells.

To test whether $\mathrm{Mn}$ and factors released from microglia can work together to affect $A \beta$ production, we repeated the experiment in APPsw-N2a cells cocultured with mouse BV2 microglial cells. Under this condition, Mn treatment $(100 \mu \mathrm{M}$ for $24 \mathrm{~h})$ significantly increased BACE1 by $103.84 \pm 16.42 \%(n=5)$ and PS1 by $37.75 \pm 5.33 \%$ $(n=5 ; p<0.05)$, and reduced ADAM10 by $22.77 \pm 6.20 \%$ ( $p<0.05$, two-way ANOVA), respectively, in APPsw-N2a cells (Figures 5A-D); APP, C99, and A $\beta$ were also increased by $51.89 \pm 17.27 \%(n=5), 48.21 \pm 8.28 \%(n=5)$ and $210.26 \pm 27.14 \%(n=5)$, respectively $(p<0.05)$, while the non-amyloidosis-processing product C83 was decreased by $35.40 \pm 12.52 \%(n=5 ; p<0.05$, two-way ANOVA; Figures 5E-I). 

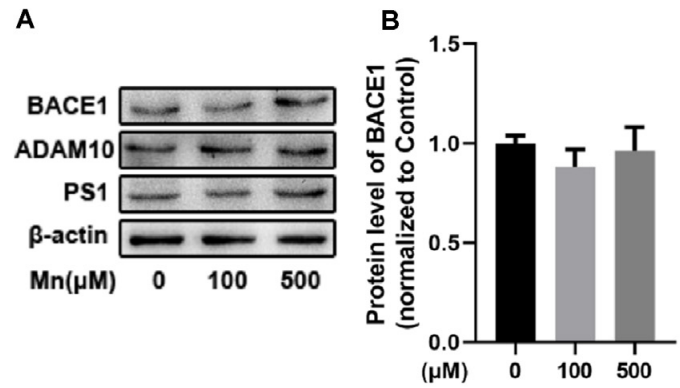

$\mathbf{E}$

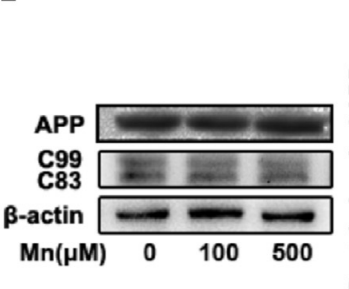

$\mathbf{F}$

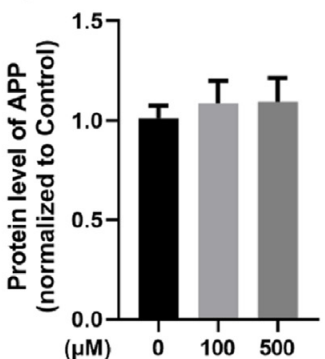

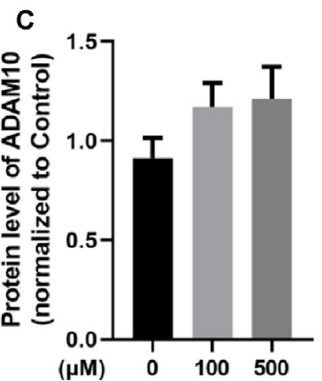

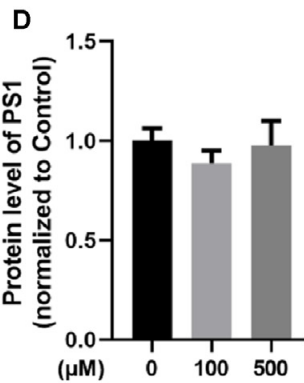

G

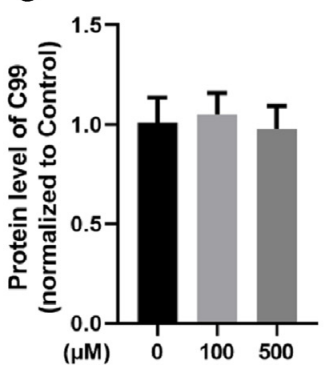

H

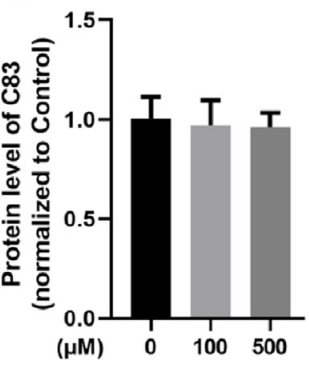

FIGURE 4 | Mn-exposure did not influence amyloidogenic processing of APP in N2a cells transfected with APPsw. (A-D) Western blot analysis was carried out to examine the expression levels of APP cleavage enzymes, BACE1, ADAM10, and PS1, in APPsw-N2a cells. $\beta$-actin was used as an internal control. No significant change was detected in the protein levels of BACE1, ADAM10, and PS1 in 100 or $500 \mu \mathrm{M}$ Mn-treated APPsw-N2a cells. (E-H) Western blot analysis was used to determine the protein levels of C99 and C83 in 100 or $500 \mu \mathrm{M}$ Mn-treated APPsw-N2a cells. There were no significant changes in the C99 and C83 level in Mn-treatment cells compared with the controls. $n=5$ mice for each group, $p>0.05$, one-way ANOVA.
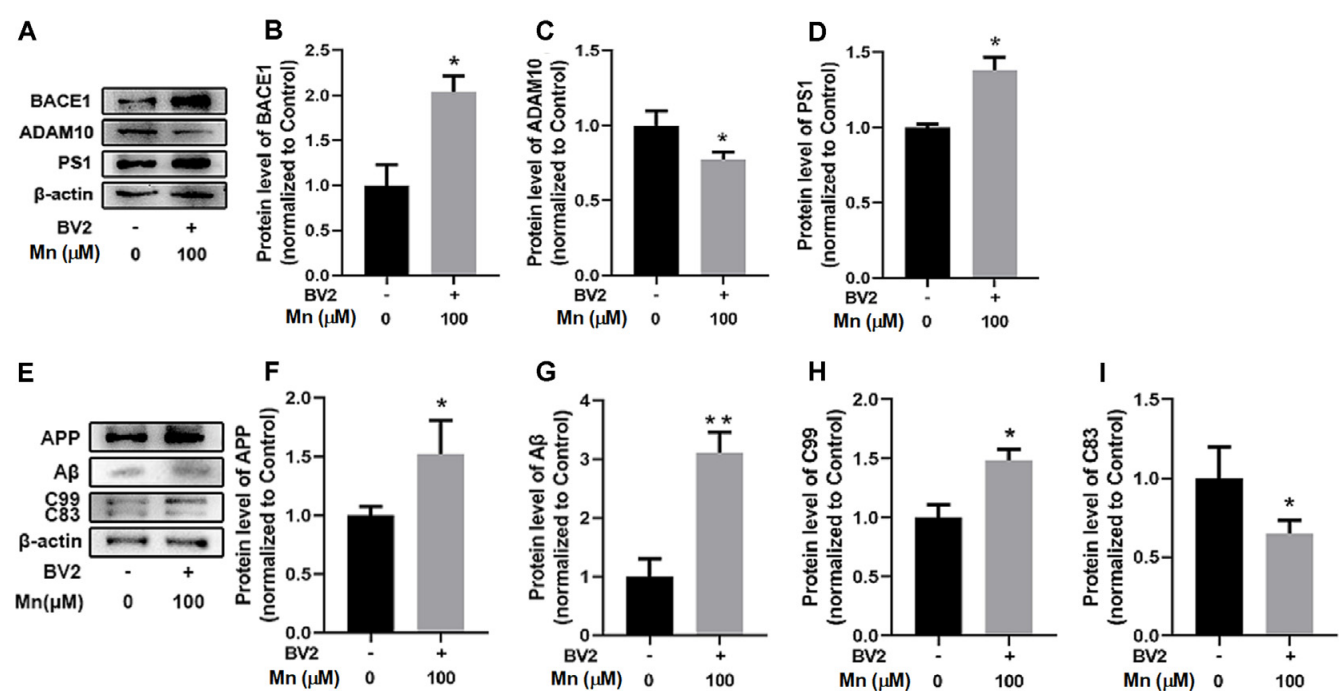

FIGURE 5 | Mn enhances amyloidogenic APP processing in APPsw-N2a cells cocultured with microglia BV2 cells. (A-D) Western blot analyses of the protein levels of BACE1, ADAM10, and PS1 in APPsw-N2a cells. Example gel images are shown with $\beta$-actin as the internal control (A). BACE1 level (B) and PS1 level (D) were increased, but ADAM10 level (C) was decreased, in $100 \mu \mathrm{M}$ Mn-treated APPsw-N2a cells cocultured with BV2, compared with the control group. (E-I) Western blot analyses were carried out to examine the protein expression levels of APP, C99, C83, and AB in APPsw-N2a cells (E). Mn treatment, $100 \mu \mathrm{M}$, significantly increased the protein levels of APP (F), AB (G), and C99 (H) in APPsw-N2a cells cocultured with BV2, compared with the control group; in contrast, $100 \mu \mathrm{M}$ Mn treatment significantly decreased in the protein levels of C83 (I) in APPsw-N2a cells cocultured with BV2 compared with the control group. All data are means \pm SE. ${ }^{*} p<0.05$, ${ }^{* *} p<0.01$, two-way ANOVA, $n=5$ for each group.

To further determine how Mn and microglia work together to promote amyloidogenic APP processing in APPsw-N2a cells described above, we treated APPsw-N2a cells with microglia-conditioned media (MCM) from BV2 microglia with or without Mn treatment. Protein Western blot showed that treatment of APPsw-N2a cells with $100 \mu \mathrm{M}$ Mn did not 

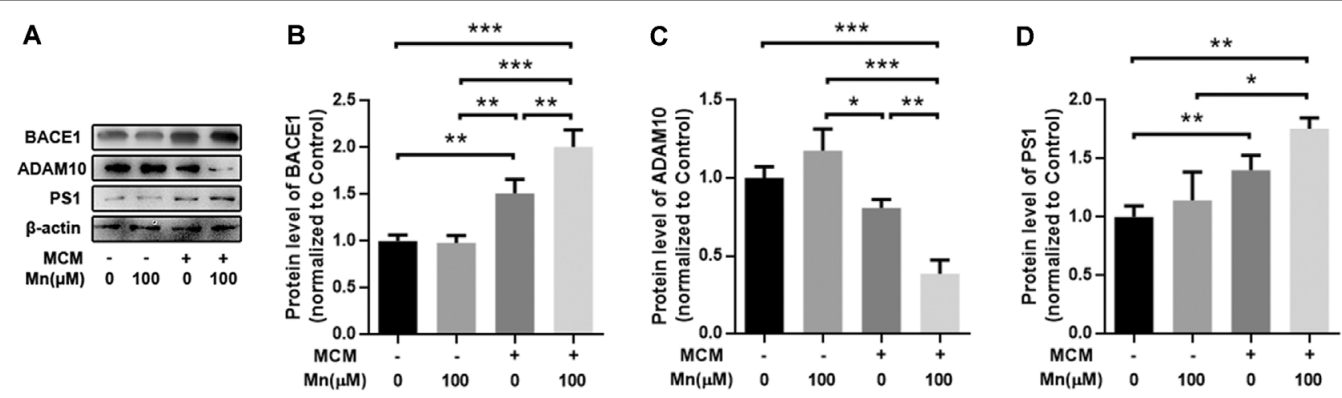

E

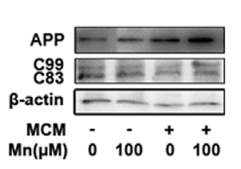

$\mathbf{F}$
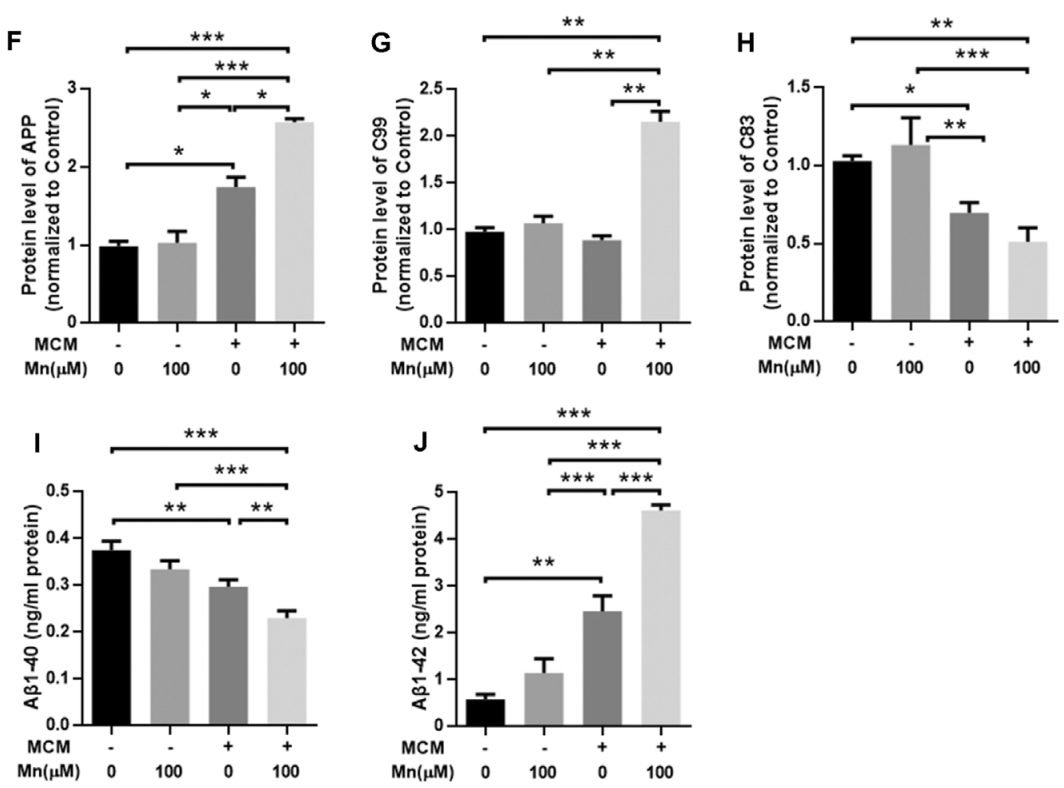

FIGURE 6 | Amyloidogenic processing of APP was enhanced in APPsw-N2a cells cultured with microglia-conditioned media (MCM) from Mn-treated BV2 cells. (A-D) Western blot results on the expression levels of APP cleavage enzymes, BACE1, ADAM10, and PS1 in APPsw-N2a cells under different conditions. MCM, especially MCM from Mn-treated BV2 cells, significantly increased the levels of BACE1 (B) and PS1 (D). MCM from Mn-treated BV2 cells also significantly decreased the level of ADAM10 (C) in APPsw-N2a cells. (E-H) Western blot results on the expression levels of APP, C99, and C83 in APPsw-N2a cells. $\beta$-actin was used as an internal control. APP and C99 levels were increased in APPsw-N2a cells cultured with MCM from Mn-treated BV2 cells compared with vehicle, Mn alone, MCM alone groups (F,G). C83 levels were decreased in APPsw-N2a cells cultured with MCM from Mn-treated BV2 cells compared with the other three groups $\mathbf{( H )}$. (I,J) Enzyme-linked immunosorbent assay (ELISA) data showing that Mn, MCM, especially MCM from Mn-treated BV2 cells increased A $31-42$ secretion (I) and decreased A $\beta 1-40$ production (J) in APPsw-N2a cells. ${ }^{*} p<0.05,{ }^{\star *} p<0.01,{ }^{\star \star *} p<0.001$, two-way ANOVA, $n=5$ for each group.

change the levels of APP, BACE1, ADAM10, PS1, A $\beta 1-42$, and $A \beta 1-40$ compared with the control (Figure 6). Exposure to MCM from normal microglia increased BACE1 $(n=5$, $P<0.05$, two-way ANOVA, Figures 6A,B) and PS1 $(n=5$, $p<0.05$, two-way ANOVA; Figures 6A,D), whereas a slight, but not significant, decrease in the level of ADAM10 $(p>0.05$, two-way ANOVA; Figures 6A,C) compared with the control group. MCM treatment increased APP $(n=5$, $p<0.05$, two-way ANOVA; Figures 6E,F) and A $\beta 1-42$ $(p<0.05$, two-way ANOVA; Figure 6J), but reduced C83 $(n=5, p<0.05$; Figures 6E,H) and A $\beta 1-40(p<0.05$, two-way ANOVA; Figure 6I). Additionally, treatment with MCM from $100 \mu \mathrm{M}$ Mn-exposed microglia further increased BACE1 $(n=5, p<0.01$, two-way ANOVA; Figures 5A,B) and PS1 ( $p<0.05$, two-way ANOVA; Figures 6A,D) but decreased the level of ADAM10 $(p<0.05$, two-way ANOVA; Figures 6A,C) in APPsw-N2a cells compared with both vehicle control and Mn-treatment alone. Furthermore, treatment with MCM from $100 \mu \mathrm{M}$ Mn-exposed microglia also increased C99 ( $p<0.05$, two-way ANOVA; Figures 6E,G) and A $\beta 1-42$ $(n=5, p<0.05$, two-way ANOVA; Figure 6J), but reduced C83 $(n=5, p<0.05$; Figure 6H) and A $\beta 1-40(n=5$, $p<0.05$, two-way ANOVA; Figure 6I) compared with the vehicle control, Mn-treatment alone, and MCM from normal microglia, respectively. Taken together, these results indicate that activation of microglia and their consequent release of inflammatory cytokines may be involved in the amyloidogenic effect of chronic Mn treatment.

\section{Mn Effects on Inflammatory Responses in $3 \times \mathrm{Tg}-\mathrm{AD}$ Mouse Brains and BV2 Microglial Cells}

To examine the possibility that $\mathrm{Mn}$ enhancement of $\mathrm{A} \beta$ production/accumulation requires inflammatory cytokines from 
microglia, we analyzed the proinflammatory cytokines, IL-1 $\beta$ and TNF- $\alpha$. Western blot and ELISA analyses showed that IL$1 \beta$ and TNF- $\alpha$ levels were increased significantly in Mn-treated BV2 microglia culture supernatants compared with the control BV2 microglia cells $(n=5, p<0.01$, one-way ANOVA, Figures 7A,A1-A3). Then we used ELISA to measure the levels of IL- $1 \beta$ and TNF- $\alpha$ in the culture supernatants of APPsw-N2a cells treated with either Mn-containing or Mn-free MCM. We detected substantial differences in the level of IL- $1 \beta$ and TNF- $\alpha$ in the supernatants from the four groups of APPsw-N2a cell cultures: treatment with $100 \mu \mathrm{M}$ Mn did not alter the level of IL$1 \beta$ and TNF- $\alpha$, treatment with MCM caused significant increase in the level of IL- $1 \beta$ and TNF- $\alpha(n=5, p<0.05$, one-way ANOVA, Figures 7B,B1,B2); more important, treatment with $100 \mu \mathrm{M}$ Mn-containing MCM further increased the levels of IL- $1 \beta$ and TNF- $\alpha(n=5, p<0.05$, two-way ANOVA, Figures 7C,C1,C2).

To provide evidence for $\mathrm{Mn}$ activation of microglial cells in amyloidogenesis in intact animal $\mathrm{AD}$ models, we examined microglia in $3 \times \mathrm{Tg}-\mathrm{AD}$ mouse brain in the $\mathrm{Mn}$ group and Control group by immunostaining Iba1, a marker for microglia and its activation upon stimulation. As shown in Figure 8A, chronic $\mathrm{Mn}$ exposure increased Iba1-positive microglia and inflammatory foci in CA1, CA3, and DG of $3 \times \mathrm{Tg}-\mathrm{AD}$ mouse hippocampus compared with the Control group. Moreover, Iba1-positive microglia appeared in florid $\mathrm{A} \beta$ plaques in $\mathrm{CA} 3$ region of $\mathrm{Mn}$-treated $3 \times \mathrm{Tg}-\mathrm{AD}$ mice (Figure 8A). In addition, Western blot analysis showed that chronic Mn exposure elevated the protein level of inflammatory cytokines IL- $1 \beta$ and TNF- $\alpha$ in the cerebral cortex and hippocampus ( $p<0.05$, two-way ANOVA; Figures 8B,B1-B3). These results provide evidence that in the $3 \times \mathrm{Tg}-\mathrm{AD}$ mice, chronic $\mathrm{Mn}$ exposure promote microglia activation and hence production and secretion of pro-inflammatory factors that in turn increase amyloidogenesis.

\section{DISCUSSION}

The main findings of our present study are that chronic increase in brain Mn enhances amyloidogenesis in $3 \times \mathrm{Tg}-\mathrm{AD}$ mice and cultured APPsw-expressing cells, and this Mn effect requires microglia activation and the likely release of inflammatory cytokines from activated microglia. These are novel findings that had not been reported before; thus our present study advances our understanding about Mn's pro-amyloidogenic effects and the underlying cellular and molecular mechanisms.

\section{Chronic Increase in Brain Mn Increases APP Gene Expression and Amyloidogenic APP Protein Processing}

While sufficient amounts of Mn are necessary for the human body and neurons to function normally (Horning et al., 2015), excessive $\mathrm{Mn}$ accumulation in the brain was shown to impair cognition and to be a risk factor for developing dementia and $\mathrm{AD}$ (Banta and Markesbery, 1977; Bowman et al., 2011; Tuschl et al., 2013; Tong et al., 2014; Wang et al., 2017), but the underlying

\section{A Western blot data from BV2 microglia culture}
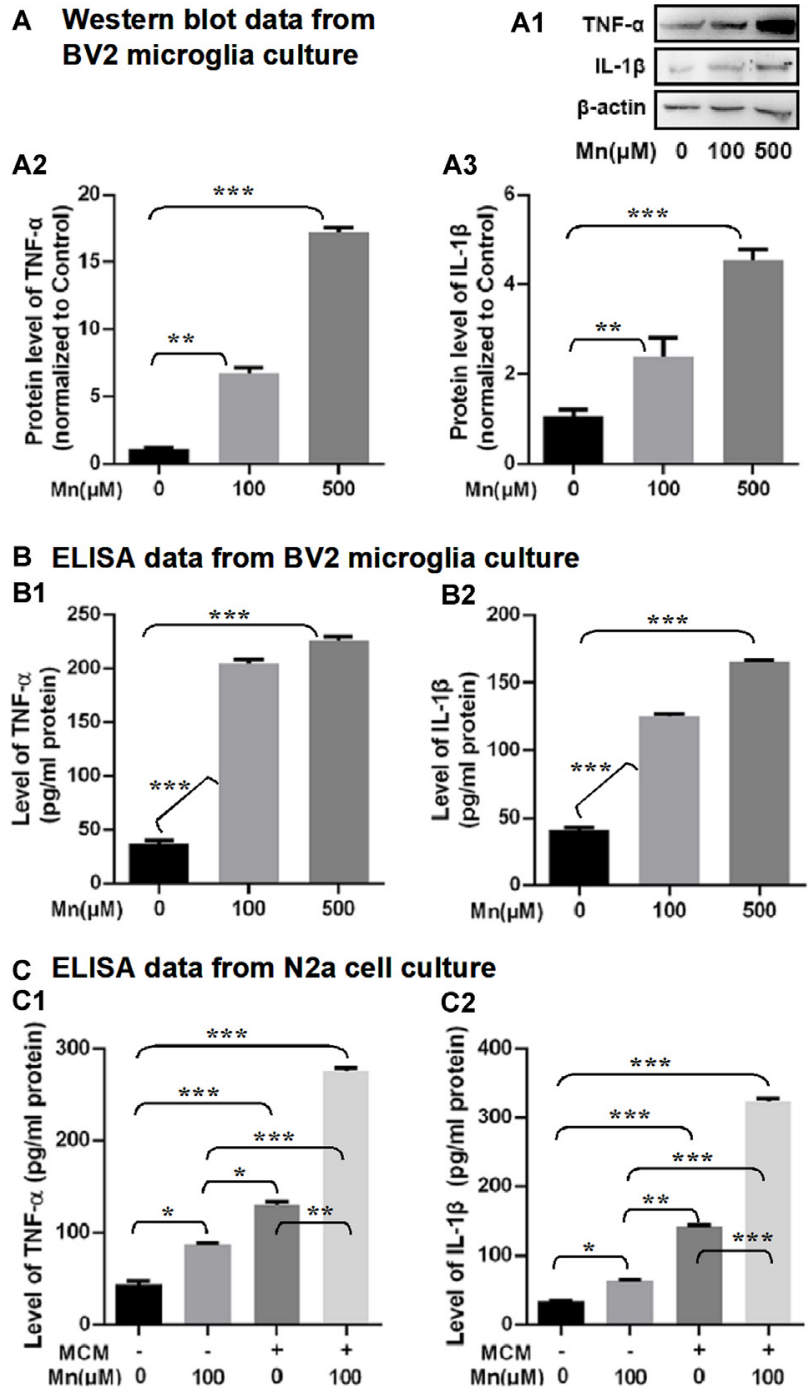

FIGURE 7 | Effects of Mn exposure on the secretion of TNF- $\alpha$ and IL-1 $\beta$ in BV2 microglia and APPsw-N2a cells treated with a conditioned medium collected from BV2 cells in the absence or presence of $100 \mu \mathrm{M} \mathrm{Mn}$ for $24 \mathrm{~h}$. (A: A1-A3) Western blots showing that 100 and $500 \mu \mathrm{M}$ Mn treatment for $24 \mathrm{~h}$ each increased the protein levels of TNF- $\alpha$ and IL-1 $\beta$ in BV2 cells. $\beta$-actin served as internal control. (B: B1,B2) ELISA data showing that both $100 \mu \mathrm{M} \mathrm{Mn}$ and $500 \mu \mathrm{M}$ Mn treatment for $24 \mathrm{~h}$ increased the secretion and release of TNF- $\alpha$ and IL-1 $\beta$ in BV2 cells. (C: $\mathbf{C 1 , C 2 ) ~ E L I S A ~ d a t a ~ s h o w i n g ~ t h a t ~}$ the secretion of TNF- $\alpha$ and IL-1 $\beta$ significantly increased in APPsw-N2a cells treated with Mn, MCM, especially MCM from Mn-treated BV2 cells.

APPsw-N2a cells were treated with a conditioned medium collected from BV2 cells in the absence or presence of $100 \mu \mathrm{M} \mathrm{Mn}$ for $24 \mathrm{~h} .{ }^{*} p<0.05$, ${ }^{\star \star} p<0.01,{ }^{* \star *} p<0.001$, one-way ANOVA for $(\mathbf{A}, \mathbf{B})$, two-way ANOVA for $(\mathbf{C})$, $n=5$ for each group.

molecular mechanisms are not fully understood. In young adult macaque monkeys, chronic (10 months) Mn overexposure upregulated the expression of amyloid-beta precursor-like protein-1, induced formation of diffuse $A \beta$ plaques in the frontal cortex, and also triggered degenerative changes in cortical neurons of these Mn-treated monkeys (Guilarte et al., 2008; Guilarte, 2010). However, the molecular mechanisms of these 
A Qualitative immunofluorescence detection of $A \beta$ and lba1
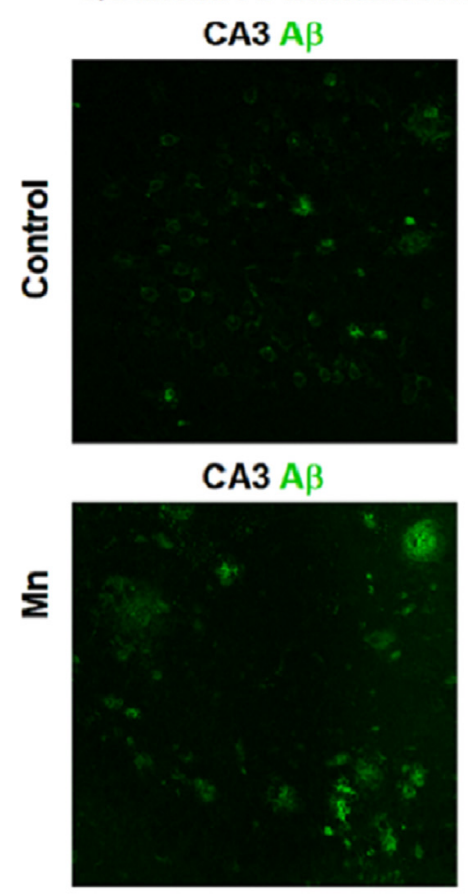

CA3 Iba1

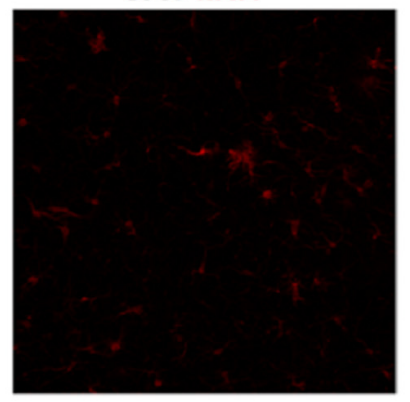

CA3 Iba1

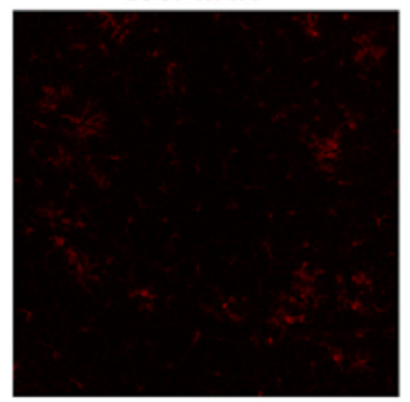

A $\beta$ /ba1 merged

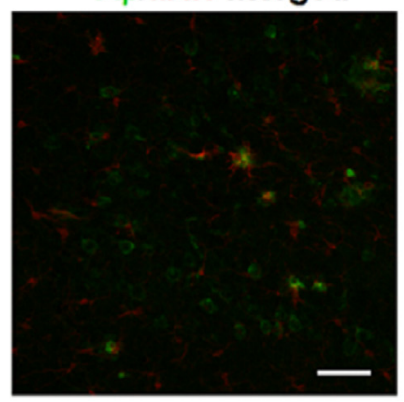

$A \beta / b a 1$ merged

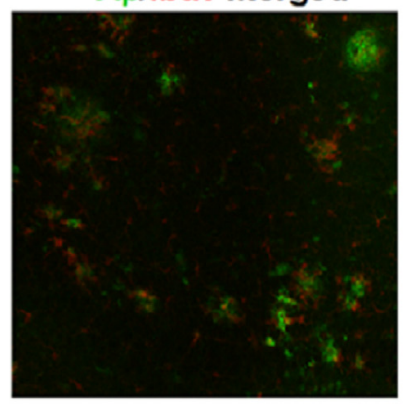

B Quantitative western blot analysis of TNF- $\alpha$ and IL-1 $\beta$

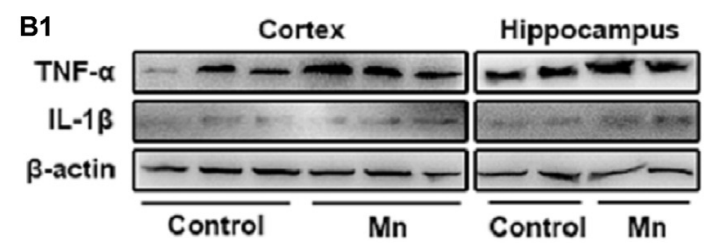

B2

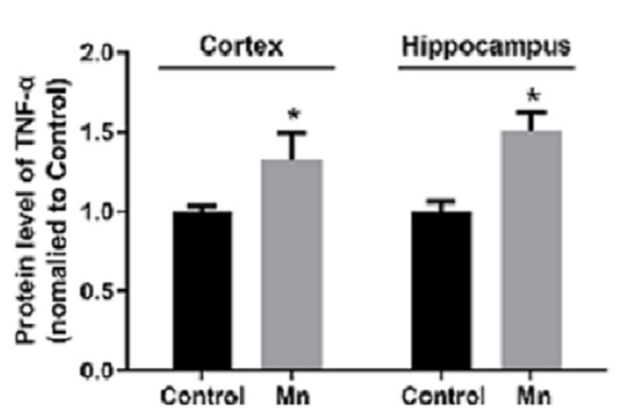

B3

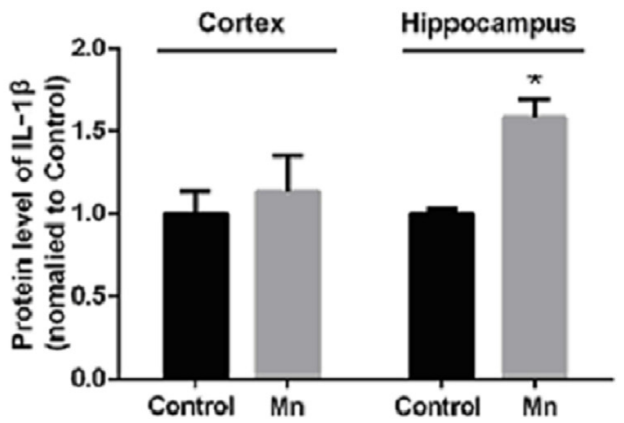

FIGURE 8 | Mn treatment increased microglia inflammatory reaction in 3xTg-AD mouse brains. (A) Qualitative exemplary confocal microscopic images showing that $A \beta$ (green) was clearly increased, Iba1 signal (red, a marker for microglia) was stronger, and lbal-labeled microglia were more numerous and in clusters, indicating microglial activation in the hippocampal CA3 area in chronic Mn-treated 3×Tg-AD mice. Scale bar = $40 \mu \mathrm{m}$. (B: B1-B3) Western blot quantitative analyses showing the expression levels of TNF- $\alpha$ and IL- $1 \beta$ in the cortex and hippocampus of the $3 \times \mathrm{Tg}$-AD mice following chronic Mn treatment. $\beta$-actin served as internal control. ${ }^{*} p<0.05$, two-way ANOVA, $n=5$ for each group.

Mn effects are not fully understood. Clearly, additional data are needed to more firmly establish Mn's pro-amyloidogenic effects and the underlying molecular mechanisms.

Therefore, our present study examined the effects of $\mathrm{Mn}$ on the development of $\mathrm{AD}$ pathology in $3 \times \mathrm{Tg}-\mathrm{AD}$ mouse model (Oddo et al., 2003) and in a cell line stably expressing human Swedish mutant APP (APPsw-N2a cells). More important, because of the critical role of $A \beta$ production in AD pathogenesis (Selkoe and Hardy, 2016; Forner et al., 2017; Walsh and Selkoe, 2020), we sought to identify the mechanisms by which $M n$ regulates $A \beta$ generation and accumulation in the transgenic $3 \times \mathrm{Tg}-\mathrm{AD}$ mice (Oddo et al., 2003). We found that 


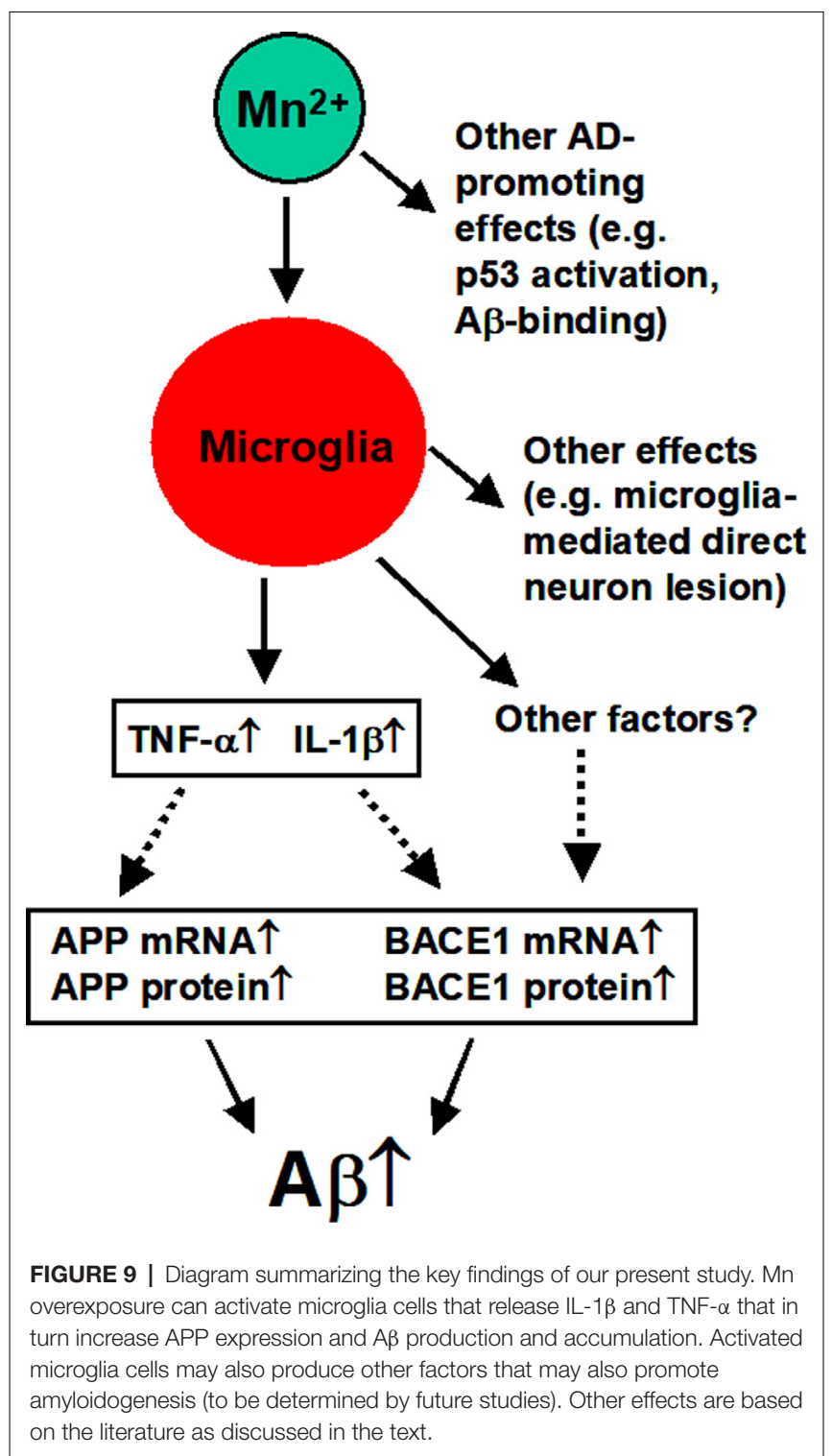

chronic Mn treatment increased A $\beta$ plaques in the cerebral cortex and hippocampus, resulting from elevated APP gene and protein expression, BACE-1 gene and protein expression, and hence increased $A \beta$ production and accumulation; simultaneously, $\mathrm{Mn}$ treatment reduced the non-amyloidogenic APP cleavage pathway by decreasing the expressing of ADAM10, a key component of $\alpha$-secretase activity. These results indicate a new molecular basis for the clinical and experimental finding that high $\mathrm{Mn}$ in the brain is a risk factor to develop AD pathology and cognitive impairments, that is, Mn can increase both APP gene expression and amyloidogenic APP processing that produces $A$ $1-42$. These are novel and important results that improve our understanding on $\mathrm{Mn}$ effects on $\mathrm{AD}$ pathogenesis.

We need to note here that in this study, the effects of $\mathrm{Mn}$ treatment were obtained by comparing baseline (no Mn-treated) $3 \times \mathrm{Tg}-\mathrm{AD}$ mice with $\mathrm{Mn}$-treated $3 \times \mathrm{Tg}-\mathrm{AD}$ mice; such a comparison is a valid design that investigates if and how Mn affects $A \beta$ production and accumulation in genetically $\mathrm{AD}$-predisposed animals. Future studies will need to determine Mn's potential amyloidogenic effects in normal animals.

\section{Mn Enhancement of Microglial Activation and Secretion of Inflammatory Cytokines Is Required for Mn Increase of Amyloidogenesis}

Our results show, surprisingly, that $\mathrm{Mn}$ alone did not affect APP and BACE1 expression and $A \beta$ generation; in APPsw-N2a cells, in contrast, when the APPsw-N2a cells were cocultured with microglia or cultured in a microgliaconditioned medium, Mn treatment increased the expression level of APP, BACE1, amyloidogenic C99 fragment, and $\mathrm{A} \beta$; we also found that $\mathrm{Mn}$ treatment increased microgliareleased inflammatory cytokines IL-1 $\beta$ and TNF- $\alpha$ in microglia culture and an increase in activated microglia in $3 \times \mathrm{Tg}-\mathrm{AD}$ mouse brains. These results are consistent with the fact that microglia are key innate immunoreactive cells in the brain that release proinflammatory cytokines when activated, and neuroinflammation is a key component of AD pathogenesis (Minter et al., 2016; Forner et al., 2017; Hansen et al., 2018; Nichols et al., 2019; Simon et al., 2019). It has been reported that $\mathrm{Mn}$ can induce microglia activation and neuroinflammation that caused hippocampal functional impairment (Wang et al., 2017). Previous studies also reported that $\mathrm{Mn}$ can activate microglia that in turn release proinflammatory cytokines IL- $1 \beta$ and TNF- $\alpha$, leading to neuroinflammation, which in turn causes neuronal cell damage (Liu, 2006; Zhang et al., 2010; Park and Chun, 2017). Additionally, proinflammatory cytokines, especially IL-1 $\beta$ elevation has been detected in AD patients (Cacabelos et al., 1991; Griffin et al., 2000; Forlenza et al., 2009) and in the brains of aged AD model mice (Lim et al., 2000; Ghosh et al., 2013). Thus, our present findings are important. Our present study in $3 \times \mathrm{Tg}-\mathrm{AD}$ mice are also generally consistent with literature data indicating that Mn may impair hippocampusdependent memory in rats and WT mice (Fu et al., 2016; Wang et al., 2017).

However, we need to note the following limitations of our results. First, besides IL- $1 \beta$ and TNF- $\alpha$, microglia cells may release other factors that may partially mediate Mn-stimulated amyloidogenesis. Second, in our present study, we did not identify the states (M1 proinflammatory state vs. M2 state) of the microglial cells (Orihuela et al., 2016), but we speculate that the microglia cells associated with our observed effects were likely in the M1 state because we detected an increased release of IL- $1 \beta$ and TNF- $\alpha$, and these proinflammatory cytokines that are commonly released from the M1 proinflammatory state. Future studies will need to determine these possibilities.

How Mn-triggered microglial IL- $1 \beta$ and $T N F-\alpha$ release subsequently increases APP production, BACE1 expression, and $\beta$-secretase activity (amyloidogenic) and decreases ADAM10/asecretase activity (non-amyloidogenic) are currently not known, 
and even how Mn treatment affects IL- $1 \beta$ and TNF- $\alpha$ release was not settled in previous studies with conflicting results from cell and animal AD models (Domingues et al., 2017). Our present study has provided new data and advanced this field, although additional studies are required to obtain a more complete understanding.

\section{CONCLUDING REMARKS}

In summary, as diagramed in Figure 9, our study indicates that in the $3 \times \mathrm{Tg}-\mathrm{AD}$ mice and cultured APPsw-expressing cells, $\mathrm{Mn}$ increases amyloidogenic APP processing and $\mathrm{A} \beta$ production, and these $\mathrm{Mn}$ effects require microglia activation and the likely release of inflammatory cytokines. Thus, Mn enhancement of microglia activation cannot only lesion the brain neurons directly via the established cytokine-based mechanisms (Minter et al., 2016; Hansen et al., 2018; Nichols et al., 2019; Simon et al., 2019) but also by increasing APP expression and amyloidogenic APP processing, contributing to AD pathogenesis and neurodegeneration.

\section{DATA AVAILABILITY STATEMENT}

The raw data supporting the conclusions of this article will be made available by the authors, without undue reservation, to any qualified researcher.

\section{REFERENCES}

Adlard, P. A., and Bush, A. I. (2018). Metals and Alzheimer's disease: how far have we come in the clinic? J. Alzheimers Dis. 62, 1369-1379. doi: 10.3233/JAD170662

Alzheimer's Association. (2020). 2020 Alzheimer's disease facts and figures. Alzheimers Dement. doi: 10.1002/alz.12068 [Epub ahead of print].

Ayton, S., Lei, P., and Bush, A. I. (2013). Metallostasis in Alzheimer's disease. Free Radic. Biol. Med. 62, 76-89. doi: 10.1016/j.freeradbiomed.2012.10.558

Banta, R. G., and Markesbery, W. R. (1977). Elevated manganese levels associated with dementia and extrapyramidal signs. Neurology 27, 213-216. doi: 10.1212/wnl.27.3.213

Bowler, R. M., Roels, H. A., Nakagawa, S., Drezgic, M., Diamond, E., Park, R., et al. (2007). Dose-effect relationships between manganese exposure and neurological, neuropsychological and pulmonary function in confined space bridge welders. Occup. Environ. Med. 64, 167-177. doi: 10.1136/oem.2006. 028761

Bowman, A. B., Kwakye, G. F., Herrero Hernández, E., and Aschner, M. (2011). Role of manganese in neurodegenerative diseases. J. Trace Elem. Med. Biol. 25, 191-203. doi: 10.1016/j.jtemb.2011.08.144

Cacabelos, R., Barquero, M., Garcia, P., Alvarez, X. A., and Varela de Seijas, E. (1991). Cerebrospinal fluid interleukin-1 $\beta$ (IL-1 $\beta$ ) in Alzheimer's disease and neurological disorders. Methods Find. Exp. Clin. Pharmacol. 13, 455-458.

Cheignon, C., Tomas, M., Bonnefont-Rousselot, D., Faller, P., Hureau, C., and Collin, F. (2018). Oxidative stress and the amyloid $\beta$ peptide in Alzheimer's disease. Redox Biol. 14, 450-464. doi: 10.1016/j.redox.2017. 10.014

Chen, P., Chakraborty, S., Mukhopadhyay, S., Lee, E., Paoliello, M. M., Bowman, A. B., et al. (2015). Manganese homeostasis in the nervous system. J. Neurochem. 134, 601-610. doi: 10.1111/jnc.13170

Ciechanover, A., and Kwon, Y. T. (2015). Degradation of misfolded proteins in neurodegenerative diseases: therapeutic targets and strategies. Exp. Mol. Med. 47:e147. doi: 10.1038/emm.2014.117

\section{ETHICS STATEMENT}

The animal study was reviewed and approved by the Laboratory Animal Ethics Committee of China Medical University which approved all experimental procedures.

\section{AUTHOR CONTRIBUTIONS}

GL, XL, and WZ: conceptulization, design, data collection and analysis, and manuscript writing. XC and NZ: data collection and analysis. All authors contributed to the article and approved the submitted version.

\section{FUNDING}

This work was supported by grants from the Natural Science Foundation of China (81471112, 81000468, 81771174, and 81601113).

\section{ACKNOWLEDGMENTS}

We thank Professor Francesca-Fang Liao of the University of Tennessee Health Science Center, USA, for her expert comments and meticulous editing of the multiple versions of this manuscript. We also thank Ms. Sarah Grace Lebovitz of the University of Tennessee Health Science Center, USA, for her careful language editing of this manuscript.

Correa, F. G., Hernangómez, M., and Guaza, C. (2013). Understanding microglianeuron cross talk: relevance of the microglia-neuron cocultures. Methods Mol. Biol. 1041, 215-229. doi: 10.1007/978-1-62703-520-0_20

Daoust, A., Saoudi, Y., Brocard, J., Collomb, N., Batandier, C., Bisbal, M., et al. (2014). Impact of manganese on primary hippocampal neurons from rodents. Hippocampus 24, 598-610. doi: 10.1002/hipo.22252

Domingues, C., da Cruz, E. S. O. A. B., and Henriques, A. G. (2017). Impact of cytokines and chemokines on Alzheimer's disease neuropathological hallmarks. Curr. Alzheimer Res. 14, 870-882. doi: 10.2174/1567205014666170317113606

Ellingsen, D. G., Konstantinov, R., Bast-Pettersen, R., Merkurjeva, L., Chashchin, M., Thomassen, Y., et al. (2008). A neurobehavioral study of current and former welders exposed to manganese. Neurotoxicology 29, 48-59. doi: 10.1016/j.neuro.2007.08.014

Forlenza, O. V., Diniz, B. S., Talib, L. L., Mendonca, V. A., Ojopi, E. B., Gattaz, W. F., et al. (2009). Increased serum IL-1 $\beta$ level in Alzheimer's disease and mild cognitive impairment. Dement. Geriatr. Cogn. Disord. 28, 507-512. doi: 10.1159/000255051

Forner, S., Baglietto-Vargas, D., Martini, A. C., Trujillo-Estrada, L., and LaFerla, F. M. (2017). Synaptic impairment in Alzheimer's disease: a dysregulated symphony. Trends Neurosci. 40, 347-357. doi: 10.1016/j.tins.2017. 04.002

Fu, H. H., Chen, W., Yu, H., Wei, Z., and Yu, X. (2016). The effects of preweaning manganese exposure on spatial learning ability and p-CaMKII $\alpha$ level in the hippocampus. Neurotoxicology 52, 98-103. doi: 10.1016/j.neuro.2015. 11.013

Garcia, S. J., Gellein, K., Syversen, T., and Aschner, M. (2006). A manganeseenhanced diet alters brain metals and transporters in the developing rat. Toxicol. Sci. 92, 516-525. doi: 10.1093/toxsci/kfl017

Ghosh, S., Wu, M. D., Shaftel, S. S., Kyrkanides, S., LaFerla, F. M., Olschowka, J. A., et al. (2013). Sustained interleukin-1 $\beta$ overexpression exacerbates tau pathology despite reduced amyloid burden in an Alzheimer's mouse model. J. Neurosci. 33, 5053-5064. doi: 10.1523/JNEUROSCI.4361-12.2013 
Griffin, W. S., Nicoll, J. A., Grimaldi, L. M., Sheng, J. G., and Mrak, R. E. (2000). The pervasiveness of interleukin-1 in Alzheimer pathogenesis: a role for specific polymorphisms in disease risk. Exp. Gerontol. 35, 481-487. doi: 10.1016/s05315565(00)00110-8

Guarneros, M., Ortiz-Romo, N., Alcaraz-Zubeldia, M., Drucker-Colín, R., and Hudson, R. (2013). Nonoccupational environmental exposure to manganese is linked to deficits in peripheral and central olfactory function. Chem. Senses 38, 783-791. doi: 10.1093/chemse/bjt045

Guilarte, T. R. (2010). APLP1, Alzheimer's-like pathology and neurodegeneration in the frontal cortex of manganese-exposed non-human primates. Neurotoxicology 31, 572-574. doi: 10.1016/j.neuro.2010.02.004

Guilarte, T. R., Burton, N. C., Verina, T., Prabhu, V. V., Becker, K. G., Syversen, T., et al. (2008). Increased APLP1 expression and neurodegeneration in the frontal cortex of manganese-exposed non-human primates. J. Neurochem. 105, 1948-1959. doi: 10.1111/j.1471-4159.2008.05295.x

Guo, C., Wang, T., Zheng, W., Shan, Z. Y., Teng, W. P., and Wang, Z. Y. (2013). Intranasal deferoxamine reverses iron-induced memory deficits and inhibits amyloidogenic APP processing in a transgenic mouse model of Alzheimer's disease. Neurobiol. Aging 34, 562-575. doi: 10.1016/j.neurobiolaging.2012. 05.009

Guo, C., Yang, Z. H., Zhang, S., Chai, R., Xue, H., Zhang, Y. H., et al. (2017). Intranasal lactoferrin enhances $\alpha$-secretase-dependent amyloid precursor protein processing via the ERK1/2-CREB and HIF-1 $\alpha$ pathways in an Alzheimer's disease mouse model. Neuropsychopharmacology 42, 2504-2515. doi: 10.1038/npp.2017.8

Hansen, D. V., Hanson, J. E., and Sheng, M. (2018). Microglia in Alzheimer's disease. J. Cell Biol. 217, 459-472. doi: 10.1083/jcb.201709069

Heid, C. A., Stevens, J., Livak, K. J., and Williams, P. M. (1996). Real time quantitative PCR. Genome Res. 6, 986-994. doi: 10.1101/gr.6.10.986

Herculano-Houzel, S. (2014). The glia/neuron ratio: how it varies uniformly across brain structures and species and what that means for brain physiology and evolution. Glia 62, 1377-1391. doi: 10.1002/glia.22683

Horning, K. J., Caito, S. W., Tipps, K. G., Bowman, A. B., and Aschner, M. (2015). Manganese is essential for neuronal health. Annu. Rev. Nutr. 35, 71-108. doi: 10.1146/annurev-nutr-071714-034419

Jenkitkasemwong, S., Akinyode, A., Paulus, E., Weiskirchen, R., Hojyo, S., Fukada, T., et al. (2018). SLC39A14 deficiency alters manganese homeostasis and excretion resulting in brain manganese accumulation and motor deficits in mice. Proc. Natl. Acad. Sci. U S A 115, E1769-E1778. doi: 10.1073/pnas. 1720739115

Jucker, M., and Walker, L. C. (2013). Self-propagation of pathogenic protein aggregates in neurodegenerative diseases. Nature 501, 45-51. doi: 10.1038/nature12481

Krishna, S., Dodd, C. A., Hekmatyar, S. K., and Filipov, N. M. (2014). Brain deposition and neurotoxicity of manganese in adult mice exposed via the drinking water. Arch Toxicol. 88, 47-64. doi: 10.1007/s00204-013 $-1088-3$

Lermyte, F., Everett, J., Lam, Y. P. Y., Wootton, C. A., Brooks, J., Barrow, M. P., et al. (2019). Metal ion binding to the amyloid $\beta$ monomer studied by native top-down FTICR mass spectrometry. J. Am. Soc. Mass Spectrom. 30, 2123-2134. doi: 10.1007/s13361-019-02283-7

Li, Y., Jiao, Q., Xu, H., Du, X., Shi, L., Jia, F., et al. (2017). Biometal dyshomeostasis and toxic metal accumulations in the development of Alzheimer's disease. Front. Mol. Neurosci. 10:339. doi: 10.3389/fnmol.2017.00339

Lim, G. P., Yang, F., Chu, T., Chen, P., Beech, W., Teter, B., et al. (2000). Ibuprofen suppresses plaque pathology and inflammation in a mouse model for Alzheimer's disease. J. Neurosci. 20, 5709-5714. doi: 10.1523/JNEUROSCI. 20-15-05709.2000

Liu, B. (2006). Modulation of microglial pro-inflammatory and neurotoxic activity for the treatment of Parkinson's disease. AAPS J. 8, E606-E621. doi: 10.1208/aapsj080369

Mastrangelo, M. A., and Bowers, W. J. (2008). Detailed immunohistochemical characterization of temporal and spatial progression of Alzheimer's diseaserelated pathologies in male triple-transgenic mice. BMC Neurosci. 9:81. doi: 10.1186/1471-2202-9-81

Minter, M. R., Taylor, J. M., and Crack, P. J. (2016). The contribution of neuroinflammation to amyloid toxicity in Alzheimer's disease. J. Neurochem. 136, 457-474. doi: 10.1111/jnc. 13411
Moldovan, N., Al-Ebraheem, A., Miksys, N. A., Farquharson, M. J., and Bock, N. A. (2013). Altered transition metal homeostasis in mice following manganese injections for manganese-enhanced magnetic resonance imaging. Biometals 26, 179-187. doi: 10.1007/s10534-012-9605-z

Mukhopadhyay, S. (2018). Familial manganese-induced neurotoxicity due to mutations in SLC30A10 or SLC39A14. Neurotoxicology 64, 278-283. doi: 10.1016/j.neuro.2017.07.030

Nichols, M. R., St-Pierre, M. K., Wendeln, A. C., Makoni, N. J., Gouwens, L. K., Garrad, E. C., et al. (2019). Inflammatory mechanisms in neurodegeneration. J. Neurochem. 149, 562-581. doi: 10.1111/jnc.14674

Oddo, S., Caccamo, A., Shepherd, J. D., Murphy, M. P., Golde, T. E., Kayed, R., et al. (2003). Triple-transgenic model of Alzheimer's disease with plaques and tangles: intracellular A $\beta$ and synaptic dysfunction. Neuron 39, 409-421. doi: 10.1016/s0896-6273(03)00434-3

Orihuela, R., McPherson, C. A., and Harry, G. J. (2016). Microglial M1/M2 polarization and metabolic states. Br. J. Pharmacol. 173, 649-665. doi: 10.1111/bph.13139

Park, E., and Chun, H. S. (2017). Melatonin attenuates manganese and lipopolysaccharide-induced inflammatory activation of BV2 microglia. Neurochem. Res. 42, 656-666. doi: 10.1007/s11064-016-2122-7

Pelvig, D. P., Pakkenberg, H., Stark, A. K., and Pakkenberg, B. (2008). Neocortical glial cell numbers in human brains. Neurobiol. Aging 29, 1754-1762. doi: 10.1016/j.neurobiolaging.2007.04.013

Peres, T. V., Schettinger, M. R., Chen, P., Carvalho, F., Avila, D. S., Bowman, A. B., et al. (2016). Manganese-induced neurotoxicity: a review of its behavioral consequences and neuroprotective strategies. BMC Pharmacol. Toxicol. 17:57. doi: 10.1186/s40360-016-0099-0

Racette, B. A. (2014). Manganism in the 21st century: the Hanninen lecture. Neurotoxicology 45, 201-207. doi: 10.1016/j.neuro.2013.09.007

Saha, U., Mowrer, J., Turner, P., Sonon, L., and Smith, R. (2015). Your household water quality: Iron and manganese. Circular 858-11. Available online at: https://www.fcs.uga.edu/docs/IronManganeseC_858-11_2.PDF.

Selkoe, D. J., and Hardy, J. (2016). The amyloid hypothesis of Alzheimer's disease at 25 years. EMBO Mol. Med. 8, 595-608. doi: 10.15252/emmm.2016 06210

Simon, E., Obst, J., and Gomez-Nicola, D. (2019). The evolving dialogue of microglia and neurons in Alzheimer's disease: microglia as necessary transducers of pathology. Neuroscience 405, 24-34. doi: 10.1016/j.neuroscience. 2018.01.059

Soto, C., and Pritzkow, S. (2018). Protein misfolding, aggregation and conformational strains in neurodegenerative diseases. Nat. Neurosci. 21, 1332-1340. doi: 10.1038/s41593-018-0235-9

Srivastava, R. A., and Jain, J. C. (2002). Scavenger receptor class B type I expression and elemental analysis in cerebellum and parietal cortex regions of the Alzheimer's disease brain. J. Neurol. Sci. 196, 45-52. doi: 10.1016/s0022510x(02)00026-6

Takeda, A., Tamano, H., Tempaku, M., Sasaki, M., Uematsu, C., Sato, S., et al. (2017). Extracellular $\mathrm{Zn}^{2+}$ is essential for amyloid $\beta 1-42$-induced cognitive decline in the normal brain and its rescue. J. Neurosci. 37, 7253-7262. doi: 10.1523/JNEUROSCI.0954-17.2017

Taylor, C. A., Hutchens, S., Liu, C., Jursa, T., Shawlot, W., Aschner, M., et al. (2019). SLC30A10 transporter in the digestive system regulates brain manganese under basal conditions while brain SLC30A10 protects against neurotoxicity. J. Biol. Chem. 294, 1860-1876. doi: 10.1074/jbc.RA118. 005628

Thomsen, H. S., Loegager, V., Noergaard, H., Chabanova, E., Moller, J. M., and Sonne, J. (2004). Oral manganese for liver imaging at three different field strengths. Acad. Radiol. 11, 630-636. doi: 10.1016/j.acra.2004.01.004

Tong, Y., Yang, H., Tian, X., Wang, H., Zhou, T., Zhang, S., et al. (2014). High manganese, a risk for Alzheimer's disease: high manganese induces amyloid- $\beta$ related cognitive impairment. J. Alzheimers Dis. 42, 865-878. doi: 10.3233/JAD140534

Tuschl, K., Mills, P. B., and Clayton, P. T. (2013). Chapter 12 -Manganese and the brain. Int. Rev. Neurobiol. 110, 277-312. doi: 10.1016/B978-0-12-410502-7. 00013-2

Walsh, D. M., and Selkoe, D. J. (2020). Amyloid $\beta$-protein and beyond: the path forward in Alzheimer's disease. Curr. Opin. Neurobiol. 61, 116-124. doi: $10.1016 /$ j.conb.2020.02.003 
Wang, D., Zhang, J., Jiang, W., Cao, Z., Zhao, F., Cai, T., et al. (2017). The role of NLRP3-CASP1 in inflammasome-mediated neuroinflammation and autophagy dysfunction in manganese-induced, hippocampal-dependent impairment of learning and memory ability. Autophagy 13, 914-927. doi: 10.1080/15548627.2017.1293766

Ward, R. J., Zucca, F. A., Duyn, J. H., Crichton, R. R., and Zecca, L. (2014). The role of iron in brain ageing and neurodegenerative disorders. Lancet Neurol. 13, 1045-1060. doi: 10.1016/S1474-4422(14)70117-6

Xue, Y., Li, J., Yan, L., Lu, L., and Liao, F. F. (2015). Genetic variability to diet-induced hippocampal dysfunction in BXD recombinant inbred (RI) mouse strains. Behav. Brain Res. 292, 83-94. doi: 10.1016/j.bbr.2015. 06.023

Yamada, M., Ohno, S., Okayasu, I., Okeda, R., Hatakeyama, S., Watanabe, H., et al. (1986). Chronic manganese poisoning: a neuropathological study with determination of manganese distribution in the brain. Acta Neuropathol. 70, 273-278. doi: 10.1007/BF00686083

Yin, L., Dai, Q., Jiang, P., Zhu, L., Dai, H., Yao, Z., et al. (2018). Manganese exposure facilitates microglial JAK2-STAT3 signaling and consequent secretion of TNF-a and IL-1 $\beta$ to promote neuronal death. Neurotoxicology 64 , 195-203. doi: 10.1016/j.neuro.2017.04.001

Zhang, P., Lokuta, K. M., Turner, D. E., and Liu, B. (2010). Synergistic dopaminergic neurotoxicity of manganese and lipopolysaccharide: differential involvement of microglia and astroglia. J. Neurochem. 112, 434-443. doi: 10.1111/j.1471-4159.2009.06477.x

Conflict of Interest: The authors declare that the research was conducted in the absence of any commercial or financial relationships that could be construed as a potential conflict of interest.

Copyright (c) $2020 \mathrm{Lin}, \mathrm{Li}$, Cheng, Zhao and Zheng. This is an open-access article distributed under the terms of the Creative Commons Attribution License (CC BY). The use, distribution or reproduction in other forums is permitted, provided the original author(s) and the copyright owner(s) are credited and that the original publication in this journal is cited, in accordance with accepted academic practice. No use, distribution or reproduction is permitted which does not comply with these terms. 